\title{
¿Qué respuesta esperaba Pablo de los Corintios en 2Cor 10-13?
}

En 2Cor 10-13 Pablo se dirige a una comunidad, Corinto, en la que su posición de apóstol ha sido puesta en entredicho debido a la llegada de unos misioneros que han causado impacto en la comunidad. Es a ella a quien la carta va dirigida, a quien el Apóstol trata de hacer reaccionar. En estos capítulos Pablo habla abundantemente de su persona, proponiéndose como el auténtico apóstol frente a las pretensiones de los misioneros intrusos, a quienes desenmascara. Pero lo hace de un modo tan peculiar y complejo que uno se ve obligado a preguntarse qué reacción esperaba de los corintios y si esa reacción era posible. Pablo se dispone a enfrentarse con una situación de desconfianza y reproches contra él. El estudio de la respuesta que pedirá a la comunidad pasa, pues, por una consideración de su propia reacción a los reproches y a la desconfianza. Reacción que es también peculiar.

Nuestro estudio tiene por objeto hallar la respuesta que Pablo pedía de la comunidad analizando ese modo peculiar, ver los interrogantes que plantea y en qué medida pueden ser respondidos. Para ello concentraremos nuestro análisis en los párrafos inicial $(10,1-11)$ y final $(12,19-13,10)$. La elección de estos párrafos no responde a una decisión arbitraria. Tras una lectura detenida de todo el texto, se ve que es en ellos donde Pablo plantea su enfoque de la situación, su comportamiento en el pasado y sus intenciones para el futuro, en cuanto a las relaciones con la comunidad. Por otra parte, el estudio exegético de estos dos párrafos será hecho en diálogo con la gran parte central, donde Pablo se concentra en argumentos concretos de la polémica contra los misioneros intrusos - pero siempre apelando a la comunidad-. Aparecerán también contactos estrechos con otros textos de la correspondencia corintia, cuyo significado habrá que hacer resaltar. Por último sacaremos las conclusiones de nuestros hallazgos.

Pero antes que nada es necesario hablar, aunque sólo sea brevemente, de dos cuestiones preliminares de crítica literaria e histórica. 
a) 2 Cor 10-13, una carta separada

El intento de saber más sobre la historia de las relaciones entre Pablo y la comunidad de Corinto va ligado indisolublemente a problemas de crítica literaria ${ }^{1}$. Concretamente, ¿es la 2 Cor una sola carta o una composición editorial de más de una carta de Pablo a los corintios? Ha habido numerosísimos intentos de dar una explicación a las distintas transiciones bruscas del texto, transiciones que en diversos casos son consideradas imposibles dentro de una misma carta. Tales son: entre 2,13 y 2,14 , entre 7,4 y 7,5 , entre 6,13 y 6,14 , entre 7,1 y 7,2 , entre los cc. 8 y 9 y entre los cc. 9 y $10-13$.

Una hipótesis clásica, con variantes más o menos complicadas, contra la unidad de la carta consiste en la inversión del orden de los capítulos. Los cc. 10-13 serían la carta -o parte de ella- escrita con lágrimas que Pablo menciona en 2,4 y 7,8-12. Habría sido escrita después de la segunda y desafortunada visita de Pablo a Corinto. Más tarde, tras las buenas noticias que trajo Tito $(7,6 \mathrm{~s})$, habría escrito los cc. 1-9, una carta de alegría y reconciliación, al mismo tiempo que de instrucciones para la colecta ${ }^{2}$.

Esta hipótesis se complica más cuando se dice que 2,13 conecta demasiado mal con 2,14 y lo mismo 7,4 con 7,5, mientras que 7,5 parece continuar con toda naturalidad el relato interrumpido en 2,13. Así pues, 2,14-7,4 sería una interpolación hecha por el editor y tomada de otra carta de Pablo. A esto se añade que 6,14-7,1 da la impresión de interrumpir no justificadamente la interpelación de Pablo, por lo que se ha considerado una interpolación que pertenecería a la «carta anterior», mencionada en 1 Cor 5,9s, y más recientemente un fragmento errático de Qumran ${ }^{3}$. Sería, pues, una interpolación dentro de otra interpolación. Según esto $2,14-6,13+7,2-4$ sería otra carta o fragmento de carta polémica, aunque en menor grado que 10-13, si bien algunos la hacen formar parte de la misma carta que estos últimos capítulos. Por otro lado, se diría que en 9,1 Pablo empieza a hablar de la colecta como si no se hubiera mencionado anteriormente en la carta. El c. 8 no habría podido precederle. Éste habría sido escrito antes de la disputa de Pablo con la comunidad. $1,1-2,13+7,5-16$ sería la carta de reconciliación y alegría.

1. Cfr. C.K. BARRETt, A Commentary on The Second Epistle to the Corinthians. London 1973, p. 17: «...the literary and historical hypotheses stand or fall together». Cfr. también p. 18.

2. Para la historia detallada del origen de esta teoría con sus representantes cfr. E.-B. Allo, Saint Paul. Seconde Epître aux Corinthiens. Paris 1956, pp. L-LVI, 254-269.

3. Cfr. J. GNILKA, «2Cor 6,14-7,1 in the light of the Qumran texts and the Testaments of the Twelve Patriarchs»: Paul and Qumran (ed. J. Murphy-O'Connor). London 1968, pp. 48-68. J.A. FITZMYER, «Qumran and the interpolated paragraph in 2Cor 6,14-7,1»: Essays on the Semitic Background of the New Testament, 1971, pp. 205-217. 
Se han intentado explicar las razones que habría tenido un editor para llevar a cabo una composición tan caprichosa, que acumularía dificultades evidentes en la secuencia ${ }^{4}$, pero no logran convencer ${ }^{5}$.

Lo más admisible desde el punto de vista de la crítica literaria es que los cc. 10-13 se resisten al intento de hacerlos pertenecer a la misma carta que los cc. 1-9. Las otras secuencias bruscas se podrían explicar dentro de la misma carta ${ }^{6}$. En el caso de 10-13 hay que admitir, con Barrett, que se trata de algo más que de una transición brusca - cosa aceptada por todos-o un cambio de humor, es más bien un cambio total de actitud, de esperanzada a desconfiada, que difícilmente puede explicarse, a no ser que Pablo hubiera recibido nuevas noticias de Corinto ?

En cuanto a la secuencia, no hay ninguna razón para suponer que los cc. 10-13 hayan sido escritos antes. Nada hay en ellos que se asemeje a lo que podía esperarse de la «carta de lágrimas». No se dice nada del incidente sobre el que, según 2Cor 2,3-5.9, trataba dicha carta. Y tampoco aparece nada en la carta de reconciliación, como sería lógico, sobre la reacción de la comunidad a la polémica de $10-13$ con los intrusos ${ }^{8}$.

Con ello nuestra opinión está en la línea de la teoría de la «quinta carta» ${ }^{9}$. Es decir, Pablo habría recibido nuevas de Corinto después de haber escrito 1-9, según las cuales la situación había empeorado. Entonces escribió 10-13. La composición editorial de 2 Cor es así más fácilmente explicable. Bastaría la desaparición del final de 1-9 o del principio de 10-13 para la fusión de ambas cartas según un orden cronológico.

Que Pablo consiguió mantener su relación con Corinto lo prueba Rom 15,26 , escrito seguramente en Corinto, donde se dice que Macedonia y Acaya contribuyeron a la colecta. La misma conservación de las cartas es un signo de ello. Pero no tiene por qué parecer extraño que no nos enteremos a través de la misma correspondencia corintia del desenlace final. No hay razón para exigir una carta-crónica que nos lo cuente.

De todas formas hay que decir que nuestros hallazgos no estarian excesivamente amenazados si una de las otras hipótesis - incluida la de la unidad de

4. Cfr. G. BoRnKAMM, «Die Vorgeschichte des sogenannten Zweiten Korintherbriefes»: Sitzungberichte der Heidelberger Akademie der Wissenschaften, Phil.-hist. Klasse, 1961, 2, pp. 24-32.

5. Cfr. los contraargumentos en C.K. BARRETT, o.c., pp. 22-25.

6. Id., 23, 96-97, 193-195, 206.

7. Id., 244.

8. Id., 23. E.-B. Allo, o.c., p. 256. H.D. BeTZ, Der Apostel Paulus und die sokratische Tradition. Eine exegetische Untersuchung zu seiner «Apologie». 2Korinther 10-13. Tübingen 1972, pp. 13, 42 .

9. Cfr. E.-B. Allo, o.c., pp. 257s. 
la 2 Cor- estuviera en lo cierto, aunque sí se muestran más sugerentes con la hipótesis aceptada. 2Cor 10-13 constituye una unidad literaria singular, con principio y final ${ }^{10}$, que plantea reflexiones específicas por sí sola.

\section{b) Los oponentes de Pablo en 2Cor 10-13}

El primero de los problemas que ha hecho verter mucha tinta a los exegetas es la identidad de los misioneros que entraron en el terreno de Pablo, o sea, en la comunidad de Corinto. Nadie duda de que eran judíos y cristianos. Basta leer 11,22. Pero unos piensan que se trataba de palestinos judaizantes, mientras que otros los caracterizan más bien como judíos helenistas -incluso gnósticos- ${ }^{11}$. Hay razones para afirmar ambas cosas. Pero para nuestro trabajo quizá lo más importante sea algo que afirma Barrett, y es que se trataba de gente que se adaptó a las exigencias de los corintios, supo exhibir los títulos que éstos pedían ${ }^{12}$.

Tampoco es decisivo para nuestro estudio si, como ya afirmaba Baur ${ }^{13} \mathrm{y}$ después mantienen Käsemann ${ }^{14}$ y Barrett ${ }^{15}$, los hyperlían apóstoloi de 11,5 y 12,11 son un grupo distinto al de los que llama pseudoapóstoloi, ergátai dólioi y servidores de Satanás disfrazados de servidores de Cristo (11,13-15). Según los autores citados los primeros serían los apóstoles de Jerusalén, mientras que el segundo grupo serían los misioneros intrusos, a quienes Pablo condena sin ambajes y que estarían comisionados por Jerusalén o al menos utilizarían su relación con Jerusalén en favor propio. Contra ellos, la mayoría de los estudiosos, con Bultmann a la cabeza ${ }^{16}$, abogan por la identidad de los hyperlían apóstoloi y los pseudoapóstoloi. En nuestra opinión hay mucho que decir

10. 10,1-11 y $12,19-13,10$ tienen todo el aspecto, como veremos, de ser párrafos inicial y final respectivamente. Cfr. infra también las reflexiones sobre la frase-parakalô inicial, que introduce el propósito principal de la carta.

11. Para la historia de las distintas opiniones cfr. D. Georgi, Die Gegner des Paulus im 2. Korintherbrief. Studien zur religiösen Propaganda in der Spätantike. Neukirchen-Vluyn 1964, pp. 7-16. G. FrIEDRICH, «Die Gegner des Paulus im 2. Korintherbrief»: Abraham unser Vater, Fest-schrift für O. Michel. Leiden/Köln 1963, pp. 191-196. C.K. BARRETT, «Paul's opponents in II Corinthians»: NTS, 17 (1970-71), 234-236, 250.

12. Cfr. C.K. BARRETT, «Paul's opponents...», pp. 248s, 252, 253s. Esto se irá viendo en el curso del estudio.

13. F.C. Baur, Paulus, der Apostel Jesu Christi. Stuttgart 1845, p. 294.

14. E. KAESEMANN, «Die Legitimität des Apostels. Eine Untersuchung zu II Korinther 1013»: ZNTW, 41 (1942) 41-48.

15. C.K. BARRETT, «Paul's opponents...», pp. 237, 242-244, 252s. A Commentary..., pp. 30-32. También se une a esa opinión B. Holmberg, Paul and Power. The structure of authority in the primitive church as reflected in the pauline epistles. Philadelphia 1980, pp. 45-48.

16. R. Bultmann, Exegetische Probleme des Zweiten Korintherbriefes. Upsala 1947. 
en favor de la primera hipótesis, aunque la decisión es difícil. En cualquier caso, nuestro análisis no requiere la solución de este problema.

\section{2 COR $10,1-11$}

Hay un criterio literario importante para estudiar este párrafo «separadamente». Se trata del paralelismo de los vv. 1-2 con 10-11, en los que se suceden términos iguales o del mismo ámbito semántico y también se repite la misma idea. Con lo cual se crea una especie de inclusión.

En los vv. 1-2 Pablo, asumiendo que es humilde, bajo (tapeinós) ${ }^{17}$, cuando está presente personalmente (katà prósopon) mientras que ausente (apón) es atrevido (tharrô), ruega que no le obliguen a ser atrevido (tharrêsai) cuando esté presente (parón).

En los vv. 10-11, paralelamente, Pablo cita la acusación que se le hace (phesín) ${ }^{18}$ : las cartas son severas y fuertes (bareîai kaì ischyraí), pero su presencia corporal (parousía toû sómatos) es débil (asthenés) y el discurso (lógos) despreciable (exoutheneménos). El que mantiene esta acusación, dice Pablo -ahora en tono de mayor amenaza que en el v. 2-, debe tener presente que tal cual es en las cartas, ausente (apóntes), así lo será también de hecho (tôi érgoi), presente (paróntes).

A partir del v. 12 comienzan los argumentos de Pablo contra los misioneros intrusos, esgrimiendo razones que demuestran su probidad. El vocabulario también cambia.

Este paralelismo de los vv. 1-2//10-11 y el tenor distinto con carácter de planteamiento de principios nos permiten considerar este párrafo como introductorio.

\section{Acusaciones y amenaza}

En estos versículos Pablo afronta directamente lo que parece ser el problema fundamental con respecto a su posición frente a la comunidad. Se trata

17. Pablo está citando acusaciones hechas contra él. Hay que hacer notar con C.K. BARRET, $A$ Commentary..., pp. 247 que «the word has not been fully accepted as descriptive of a Christian virtue».

18. B. lat sy leen phasin, lo que es una simplificación, en contra de la mayoría de los testigos. Se discute si el sentido es personal («alguno dice»: un líder de la oposición), que estaría apoyado por los vv. 7 y 11 (así C.K. BARReTr, A Commentary..., pp. 260), o impersonal («se dice») (así E.-B. Allo, o.c., pp. 248). Pero en cualquier caso lo importante para nosotros es que Pablo cita una acusación. 
del comportamiento de Pablo, que ha entrado en conflicto con el de otros misioneros (cfr. 11,20s) a los ojos de la comunidad. Mientras éstos probablemente cultivaban los recursos retóricos y sofistas, Pablo no lo hace $(11,6)$. De ahí que se califique su hablar como exoutheneménos $(10,10)$. Mientras aquéllos usaban de una presencia impositiva $(11,20)$, respaldada por la ostentación de prestigio de origen $(11,22)$, visiones $(12,1 \mathrm{ss})$ y una existencia carismática al servicio de Cristo $(11,22 \mathrm{bss})$, Pablo no lo hace, aunque se verá obligado a presumir de esas cosas en el curso de estos capítulos. Mientras los otros aceptaban ayuda económica de la comunidad, Pablo ha decidido no ser gravoso a los corintios (11,7ss; 12,13ss). En los dos textos que hablan de ello Pablo introduce el tema a partir de la comparación con los «superapóstoles» ${ }^{19}$ y en 11,7 califica esta renuncia como un rebajarse (emautòn tapeinón), término con el que se refiere también globalmente a su comportamiento en Corinto en 10,1. Todas estas cosas han sido consideradas síntomas de un déficit de fuerza en Pablo. Por eso su presencia es calificada de asthenés $(10,10)$. Pero no sólo eso, sino que, además, el comportamiento de Pablo con respecto a la comunidad cuando está ausente confirma la opinión sobre su presencia. Pablo manifiesta en sus cartas un atrevimiento y dureza en abierto contraste con lo que hace cuando está presente. Esta discrepancia entre las cartas y la presencia corporal ha hecho que, como dice Betz, la sospecha se dirija también contra las cartas ${ }^{20}$. O sea, Pablo trataría de intimidar con sus cartas, ya que es incapaz de hacerlo de persona. La conclusión es clara: alguien que se comporta así tiene que ser débil, toda la fuerza que pueda mostrar en sus cartas es aparente, y ¿cómo puede tener autoridad un apóstol débil? Así pues, presencia y ausencia de Pablo confluyen en la evaluación corintia de su fuerza, con resultado negativo.

Se debe notar que el problema de la ausencia del Apóstol no era nuevo en Corinto. Tal como aparece en nuestro texto es la elaboración conclusiva de algo que se había ido gestando. Ya en 1 Cor 4,18 dice Pablo que su ausencia ha dado lugar a que algunos se hinchen ${ }^{21}$. Más tarde, en 2 Cor 1,15-2,1, tiene que explicar por qué ha cambiado su itinerario sin pasar de nuevo por Corinto al volver de Macedonia, como había prometido en 1Cor 16,5-7. La razón que da

19. Lo hacen notar C.K. BARRETT, «Paul's opponents...», p. 246 y G. THEISSEN, The Social Setting of Pauline Christianity. Essays on Corinth. Philadelphia 1982, p. 45. Este libro es la traducción inglesa de Studien zur Soziologie des Urchristentums. Tübingen 1979, pp. 201-289.

20. H.D. BETZ, o.c., p. 45: «Die Briefstellerei scheint positiv bewertet, steht aber im Widerspruch zum persönlichen Auftreten, das Zweifellos negativ beurteilt ist. Zwischen Briefstellerei und persönlichen Auftreten ist eine deutliche Diskrepanz zu beobachten, und es ist dieser Widerspruch, der den Verdacht auch gegen die Briefstellerei wendet».

21. Cfr, infra. 
en 2 Cor 1,23 es: «por miramiento a vosotros no he vuelto a Corinto» ${ }^{22}$. Y en 2,1: «porque me impuse esta determinación, que mi ida a vosotros no fuera de nuevo objeto de tristeza». Habla inmediatamente después $(2,3 \mathrm{ss})$ de que, en vez de esa visita, escribió una carta dura que entristeció a los corintios. Ya entonces, cuando canceló su visita, Pablo tuvo que defenderse contra la acusación de obrar con ligereza, de decir «sí» y «no» al mismo tiempo (2Cor 1,1722). Y, con Barrett, tenemos que admitir que «his action was sure to be misinterpreted; and to 'spare' them is not necessarily the best way to bring spoilt children to their senses» ${ }^{23}$. La ausencia de Pablo es un problema permanente en sus relaciones con los corintios ${ }^{24}$, un problema que ellos no se sacaban de la manga. Los corintios habían recibido la carta dura, pero Pablo seguía sin aparecer. Y aún en 10-13, como veremos, existe una clara tensión entre lo que Pablo quiere hacer y lo que podría verse obligado a hacer. Su comportamiento era suficientemente ambiguo como para causar conflicto a una comunidad que no tenía los criterios tan claros como él. Y el modo que tiene Pablo de responder en esta carta podía ser interpretado perfectamente como un «sí» y un «no» al mismo tiempo.

En el capítulo de acusaciones y respuesta amenazante de Pablo hay que considerar también $2 \mathrm{~b}-4$. El v. $2 \mathrm{~b}$, continuando en la misma frase que viene desde el v. 1, introduce la raíz sárx. En los vv. 1-6 Pablo comienza a hablar aludiendo a la acusación que es presentada a modo conclusivo del párrafo en el v. 10. Asimismo, la posibilidad o amenaza de usar de atrevimiento en su visita se extiende en un período mayor que la lapidaria advertencia del v. 11. Es en esta extensión donde aparece la raíz sárx. Pablo amenaza con ser osado y atrevido con los que piensan que camina según la carne (katà sárka peripatoûntas). Dice que, aunque camina en la carne (en sarkí), no lucha según la carne (ou katà sárka strateuómetha), sus armas no son carnales (sarkiká), sino poderosas para Dios (dynatà tôi Theôi) ${ }^{25}$.

«Caminar según la carne» en nuestro texto es algo considerado malo tanto por Pablo como por los que lo piensan de él. En cambio, en sarkí gàr peripatoûntes es usado por Pablo con un sentido moralmente nuestro, aludiendo simplemente a la condición de hombre en este mundo, como lo hace en otros textos en que aparece también la expresión en sarkí (1Cor 4,11; Gal 2,20; 4,14;

22. Nos ocuparemos más adelante de este texto.

23. C.K. BARretT, A Commentary..., pp. 35s.

24. También en otras cartas se ve que Pablo sentía el problema que ocasionaba su permanente ausencia de la comunidad: Fil 2,12; Gal 4,18-20.

25. Sobre el problema de cómo debe ser entendido tôi Theôi cfr. C.K. BARretr, A Commentary..., pp. 251. Nuestra interpretación coincide con la suya y con la de E.-B. Allo, o.c., pp. 243. 
Fil 1,22; Flm 16) ${ }^{26}$. La expresión katà sárka es utilizada por Pablo en algunos textos sin connotaciones negativas, refiriéndola a la descendencia humana (Rom 1,$3 ; 4,1 ; 9,5)$, a la connacionalidad (Rom 9,3), a la existencia histórica $(1$ Cor 10,18$)$ y a los criterios humanos (1Cor 1,26$)$. Es este último uso el que insinúa ya el significado en otra serie de textos en los que caminar (Rom 8,4), ser (Rom 8,5), vivir (Rom 8,12-13), proponerse algo (2Cor 1,17), conocer $(2 \mathrm{Cor} 5,16)$, gloriarse $(2 \mathrm{Cor} 11,18)$, ser engendrado (Gal 4,23.29) katà sárka es comprendido como lo humano que se comporta antropocéntricamente, convirtiendo en absoluto la propia condición sin tener en cuenta a Dios ${ }^{27}$. En la misma línea está el adjetivo sarkikós, que sería lo que se ajusta a criterios exclusivamente humanos (1Cor 3,$3 ; 2$ Cor 1,12 ).

Por lo que se refiere a nuestro texto, es curioso que tras en sarki gàr peripatoûntes Pablo no dice ou katà sárka peripatoûmen, recogiendo $2 \mathrm{~b}$, sino que peripateîn es sustituido por strateúesthai. Con ou katà sárka strateuómetha Pablo introduce la imagen de la lucha militar, que continúa durante tres versículos. Tà gàr hópla tês strateías hemôn ou sarkiká repite la misma idea de ou katà sárka strateuómetha. Este cambio de peripateîn, más amplio (con el significado de «comportarse», "proceder»), al concreto strateúesthai tiene que ser debido al carácter concreto del reproche hecho a Pablo. Que este carácter concreto tenía que ver con la fuerza de Pablo y su capacidad para imponerse nos lo dice la imagen misma de la lucha militar que triunfa y la oposición en el v. 4 entre sarkiká y dynatá: las armas de Pablo no son carnales, sino potentes. Con todo, que katà sárka y sarkiká se mantienen en el ámbito semántico del uso paulino de la expresión en sentido negativo, lo prueba la naturaleza de la lucha de Pablo, tal como él la describe en oposición al reproche: sus armas son poderosas al servicio de Dios (tôi Theôi), combate destruyendo los pensamientos altaneros opuestos al conocimiento de Dios (katà tês gnóseos toû Theoû) y sometiendo a la obediencia de Cristo (eis tèn hypakoèn toû Christoû) ${ }^{28}$. La oposición entre la esfera humana que se absolutiza y la esfera de Dios aparece con toda claridad. Esto nos hace sospechar que el v. $2 \mathrm{~b}$ sea una formulación paulina de los reproches de sus acusadores, más bien que una cita textual de la acusación, aunque no hay modo de verificar tal posibilidad.

De todas formas es claro que en el uso de la expresión aquí lo importante es la colisión entre cómo entendía Pablo y cómo entendían quienes lo acusaban lo que está detrás de la expresión, es decir, los reproches concretos ${ }^{29}$. Se

26. En sarki aparece también en otros textos con un sentido negativo semejante al que veremos para katà sárka. Así en Rom 2,28; 7,5.18; 8,3.8s; Fil 3,3s.

27. Cfr. C.K. BarretT, A Commentary..., pp. 249s.

28. Sobre el problema del genitivo toû Christoû cfr. infra, nota 56.

29. Cfr. C.K. BARReTt, $A$ Commentary..., pp. 249: «...it is probable that what they meant by this phrase (katà sárka) was not Paul's meaning». 
trata de una confrontación de criterios diferentes en una situación determinada. Es esta diferencia de criterios puesta de manifiesto en la situación la que afecta a la utilización concreta de la expresión. Katà sárka peripatoûntas es algo general que se podría aplicar a muchos textos en los que aparece la expresión katà sárka con una actitud más concreta. En nuestro texto el significado hay que obtenerlo a partir de la concreción de la raíz sárx en torno a la imagen de la lucha militar y de lo que se contrapone a katà sárka strateuómetha y hópla sarkiká, que es hópla dynatà tôi Theôi. Dynatá se halla en el ámbito de tharrêsai y tolmêsai del v. 2, es decir, afirmaría la fuerza que se piensa que Pablo no tiene. No es aconsejable por lo tanto, como hacen algunos autores, buscar el punto de referencia concreto de katà sárka peripatoûntas privilegiando el contacto con uno de los textos en que la raíz sárx aparece con significado negativo, puesto que allí también el significado concreto nos lo da la situación que describe el contexto ${ }^{30}$. Por lo que se refiere a 2 Cor $10,2 b-4$, habría que mantenerse, pues, a partir del contexto inmediato, en el reproche genérico de falta de fuerza, que incluiría todos los aspectos citados antes que hacían que la presencia de Pablo diera la impresión de algo mediocre y falto de la categoría digna de la autoridad de un apóstol ${ }^{31}$. Y hasta es posible que el re-

30. H. WINDISCH, Der zweite Korintherbrief. Göttingen 1924, p. 295, seguido por D. GEORGI, o.c., p. 232, concreta diciendo que a Pablo se le acusaría de góes, charlatán, embaucador en la predicación, basado en la relación con 2 Cor 1,12 , donde Pablo dice que se ha conducido (anestráphemen, que sería equivalente a peripatoûntas, más amplio que los verbos utilizados en otros textos) no con sabiduría carnal (sarkikêi). Hay que objetar que ouk en sophíai sarkikêi es una concreción del anestráphemen general, debido a la situación concreta, como en 2Cor 10,3-4 lo es ou katà sárka strateuómetha y hópla sarkiká del general katà sárka peripatoûntas. El significado de la concreción sólo nos lo aclara el contexto. R. REITZENSTEIn, Die hellenistischen Mysterienreligionen nach ihren Grundgedanken und Wirkungen. Leipzig/Berlin 1927, p. 361, relaciona el reproche con el que Pablo hace a los corintios en 1Cor 3,1-3. El reproche se habría vuelto en 2 Cor 10,3-4 contra el mismo Pablo. Él también provoca contienda, luego es sarkikós y procede según la carne (katà sárka peripatountas = katà ánthropon peripateîte). Pablo se vería obligado a aclarar el carácter de su lucha. Vale aquí la misma objeción que contra Windisch. El sentido general es el mismo, pero cuando el texto concreta ya no funciona la ecuación. No es lo mismo zêlos kai éris que strateuómetha y hópla. Es de nuevo el contexto el que explica el sentido de la concreción.

31. G. Theissen, o.c., p. 45, relaciona el reproche sólo con el hecho de que Pablo no aceptaba ayuda económica de los corintios. Entonces tendría que estar preocupado de ganarse el sustento y de ahí la acusación de proceder según la carne. Contra esto habla la afirmación de Pablo en 2Cor 11,8-9 (contaba con los dones de otras iglesias para no ser gravoso en Corinto, no habla de trabajo). Theissen apoya su argumentación comparando nuestro texto con 1 Cor 9, donde $\mathrm{Pa}$ blo habla de que ha renunciado a los derechos que como apóstol tenía. Pero los contactos que descubre son forzados, sacando las palabras de sus contextos; katà sárka $(2 \mathrm{Cor} 10,3 \mathrm{~s})=$ katà ánthropon taûta lalô $(1$ Cor 9,8$)$ (además de caer en la objeción que hacíamos a Windisch y Reitzenstein, katd ánthropon se refiere a lo que Pablo está diciendo sobre el derecho a ser mantenido y no a la renuncia a él, como sería su comportamiento en 2 Cor 10,3s); strateúetai (1Cor 9,7) $=$ strateuómetha $(2$ Cor 10,3) (el verbo en 1Cor 9,7 está relacionado con el sustento, mientras que en 2 Cor 10,3 con la fuerza de Pablo al servicio de Dios); tà sarkiká $(1$ Cor 9,11)=sarkiká (2Cor 
proche incluyese también el contraste sospechoso entre la presencia insignificante y la ausencia atrevida de Pablo, como lo sugiere el hecho de que se aluda a ello al principio del período (v. 1). Como hemos visto y veremos (cfr. 13,2), la ausencia de Pablo estaba relacionada con su deseo de no actuar sin consideración con la comunidad, lo cual parece que no le impedía, para sorpresa de los corintios, hacer valer su autoridad por carta. Todo ello - al menos lo relativo a su presencia poco llamativa - sería interpretado por los intrusos y los corintios conquistados por ellos como un estar lejos de Dios, un vivir según la carne que no podía albergar en sí la fuerza carismática del apóstol.

Pablo niega que su forma de proceder sea «según la carne». No se arrepiente de su comportamiento. Pero esto lo dice al mismo tiempo que amenaza con intervenir duramente, como en el v. 11, donde se refiere a la posibilidad de ser presente como es ausente. ¿Pensaba Pablo cambiar de táctica y actuar con severidad? Entonces es que abandonaba su comportamiento «respetuoso» habitual y adoptaba el método impositivo. Y sin embargo, ¿no está diciendo que no se arrepiente, que están equivocados los que piensan que camina según la carne? Un corintio que leyera la carta tenía que percibir incluso mejor que nosotros esa dificultad de entender lo que Pablo estaba diciendo. No sería fácil para él, a partir de este primer párrafo, saber a qué atenerse. Si Pablo quería seguir como antes, ¿a qué se estaba refirienido con la amenaza? Y si no, ¿para qué complicar las cosas con discusiones acerca de su comportamiento pasado al que parece que no quiere renunciar? ¿No estaría Pablo - podrían pensar los corintios- haciendo lo mismo que otras veces, siendo duro por carta y luego, cuando está presente... nada? En Corinto sólo se le pedía que mostrara sus dotes, que se hiciera valer con la agresividad que da la conciencia de tener autoridad. Pablo responde amenazando con una intervención dura, pero discrepando de los criterios con que se le pide. Esto nos hace pensar que la respuesta que Pablo pedía de la comunidad haya que buscarla en la dirección de un cambio de criterios, como nos lo confirmará el estudio ulterior sobre otras expresiones de este mismo párrafo. Pero, en ese caso, la amenaza de una visita severa se hace problemática. Tendremos, pues, que aclarar más adelante qué lugar ocupa en el comportamiento de Pablo esta amenaza.

Antes de pasar a otro tipo de consideraciones sobre nuestro texto conviene preguntarse, en este apartado de reproches, qué significa la expresión

10,4) (allí se refiere al sustento y es opuesto a pneumatiká, mientras que aquí se refiere a armas y es opuesto a dynatá); exousía (1Cor 9,5.6.12.18=2Cor 10,8) (en 1Cor 9 se refiere a un derecho concreto, mientras que en 2 Cor $10,8=13,10$ se refiere a la autoridad apostólica que fundamenta la posibilidad de ir con severidad a Corinto: cfr. infra). H.D. BETZ, o.c., p. 96, es también injustificadamente reductor cuando afirma: «In Paulus haust ein 'Satansengel' $(12,7)$, der die Krankheit hervorruft; er wandelt also 'im Fleisch' $(10,2) \ldots »$. 
Christoû eînai del v. 7, algo en lo que Pablo se siente discriminado. Sus palabras son: «Si alguno está convencido de que es de Cristo, considere éste a su vez en sí mismo ${ }^{32}$ que, como él es de Cristo, así también nosotros». No parece probable que haya que identificar al que cree ser de Cristo, como piensa Allo, con un miembro del partido de Cristo, que utilizaba como slogan «Yo soy de Cristo» (1Cor 1,12). Este partido se habría perpetuado en Corinto y Pablo se las tendría que ver todavía con él. Lo haría utilizando irónicamente su lenguaje ${ }^{33}$. Barrett contraargumenta correctamente:

It is far from clear who the so-called «Christ-party» were, and how they were distinguished from the other groups in Corinth; but they belong to a set of divisions, or incipient divisions, in the Corinthian church as a whole, whereas we seem here to be dealing with one or more persons who had come to Corinth from without and had laid claim to the church's adherence on the ground of his, or their, special qualifications ${ }^{34}$.

Windisch distingue cuatro modos en los que se puede entender la expresión: a) ser cristiano, b) tener una relación especial con Jesús de Nazaret, c) la condición de apóstol, d) tener una relación mística de tipo gnóstico con el Cristo glorioso ${ }^{35}$. Windisch prefiere c), quizá en combinación con b). Es claro que lo que está en juego en primera instancia aquí es la autoridad de Pablo en cuanto apóstol de una comunidad y no sólo el ser cristiano. Así lo prueba el que la afirmación de ser él también de Cristo da pie a Pablo para gloriarse de la autoridad que el Señor le ha dado sobre la comunidad (v. 8), la cual, a su vez, fundamenta la amenaza de una visita severa (v. 11) ${ }^{36}$. Para tener esta autoridad se requería un status especial, que es expresado con Christô̂ eînai. Por tanto, detrás de la expresión está la pretensión de tener una relación especial con Cristo que legitima esa autoridad. En qué consiste concretamente esa relación, es difícil precisarlo. Su aspecto funcional está expresado probablemente en 11,23ss, donde Pablo responde a la pretensión de los intrusos de ser diákonoi Christoû, diciendo que lo es incluso más que ellos. Lo demuestra con

32. Aceptamos la lectura eph eautou, representada por p 46 S B L 11752495 pc., contra aph eautou de C D F G H 04402090243 M sy (En ésta y las demás notas citamos los testigos textuales según Nestle-AlAND, Novum Testamentum Graece. Stuttgart 1981, excepto en los tres casos siguientes: para el códice sinaítico usamos S; el manuscrito 044 lo citamos por su número en vez de por la letra griega psi; la letra $M$ sustituye al signo que en la citada edición de NESTLEAlAND representa al «texto mayoritario»). En cuanto al sentido cfr. E.-B. ALlo, o.c., p. 246: «...le sens, pas plus que le texte, n'est très clair; on peut comprendre 'en lui même', ou 'pour soi même', ou '(en réfléchissant) sur lui même', ou (Bachmann),(en tirant conclusion) de sa propre personne'».

34. C.K. BARretT, A Commentary..., p. 257.

35. Citado por C.K. BarretT, $A$ Commentary..., p. 256.

36. Sobre la conexión entre los vv. 8 y 9 cfr. infra. 
un catálogo de perístasis que describe una vida arriesgada, automarginada y de grandes sufrimientos al servicio del evangelio. Ésta sería la verificación funcional del ser de Cristo. Quizá detrás de la pretensión de los intrusos existía también la conexión con el Jesús histórico o con el grupo de apóstoles palestinos que se sabían herederos directos del modo de vida de Jesús y de las tradiciones sobre él ${ }^{37}$. Si fuera así, la respuesta de Pablo supondría una base completamente distinta para su pretensión de ser de Cristo ${ }^{38}$. En cualquier caso queda claro que, frente a la autoconciencia de los otros misioneros, Pablo reafirma su propia autoconciencia de tener una relación especial con Cristo, que es quien le da la autoridad y la capacidad de actuar con severidad en Corinto. Esto debe quedar muy claro ante la comunidad.

¿Qué podemos concluir de lo dicho hasta ahora sobre este párrafo inicial? Pablo, cuya conducta se ha interpretado como falta de fuerza y por tanto de autoridad apostólica, amenaza con ir a Corinto en pie de guerra para que se reconozca su autoridad. Esto parece entrar en conflicto con su comportamiento pasado, del cual no se arrepiente, sino que considera de acuerdo con su autoridad de apóstol. El texto apuntaba ya a que el combate de Pablo es contra criterios de apreciación diferentes a los suyos. Pero la amenaza sigue causando problema. Así pues, la autoridad que Pablo quiere mantener, los criterios con que ésta se puede apreciar y la amenaza de visita severa constituyen los factores que, a partir de lo dicho, configuran la misiva paulina a Corinto, factores que, como ya se ha notado, no son fácilmente articulables desde el punto de vista de un lector de la carta, en orden a provocar una respuesta. En esta dirección avanzaremos con el estudio de algunos aspectos aún no tocados en este párrafo.

37. A este respecto G. THEISSEN, o.c., p. 46, recuerda que en la tradición sinóptica (Mc 9,41) aparece la llamada a ofrecer hospitalidad a los primitivos misioneros ambulantes cristianos. La razón de la hospitalidad es hóti Christoû éste. Podría ser un indicio (unido a su alarde de ser hebreos, israelitas e hijos de Abraham: 2Cor 11,22) de la proveniencia palestina de los oponentes de Pablo y de que con Christố eînai daban expresión a su autocomprensión de pertenecer al grupo de misioneros primitivos o estar vinculados a él. Pero es difícil probarlo con una base textual tan reducida. Theissen va más allá y dice que con su pretensión de ser de Cristo los oponentes de Pablo harían valer su derecho a la hospitalidad para poder dedicarse a su misión sin distracciones. Ello implicaría la acusación contra Pablo ya vista en la interpretación que hace Theissen de «caminar según la carne» (Cfr. supra, nota 31): «he is too concerned with his material existence instead of making it something wholly dependent on his belonging to Christ» (p. 47). Como vimos en la nota 31, esto va contra lo que dice Pablo que ha hecho en 2Cor 11,8-9.

38. Cfr. C.K. BARretT, A Commentary..., p. 257: «This relationship was dependent not on the chances of history, but on the faith and the Spirit...». 


\section{Apelación de Pablo a la objetividad y cualificación de su autoridad}

Existen unas cuantas expresiones en nuestro texto, en claro contraste con la amenaza, que nos ayudan a formular la respuesta que Pablo esperaba de la comunidad:

a) 10,1-2: Autòs dè egò Paûlos parakalô hymâs dià tês praýtetos kaì epieikeías toû Christoû... déomai dè tò mè paròn tharrêsai têi pepoithései hêi logízomai tolmêsai...

Ésta es una de las frases-parakalo, cuya forma, función y sentido en las cartas paulinas ha estudiado Bjierkelund ${ }^{39}$. El autor incluye 2 Cor 10,1-2 en un primer grupo de frases en el que están además: Rom 12,1-2; 15,30-32; 16,17 ; 1 Cor 1,$10 ; 4,16$; Ef 4,1-3; 1Tes 4,10b-12; 5,14.

En cuanto a la forma:

Die Sätze werden fast immer mit dem Verb parakalô in der 1. Pers. Sing. (ev. Plur.) eingeleitet. Dann folget ebenso konsequent die kleine Konjunktion oûn oder dé. Danach steht das Objekt in der 2. Pers. Plur. hymâs, gewöhnlich in Verbindung mit adelphoí. Danach folgt in mehreren Sätzen ein präpositionaler Ausdruck. Dieser wird hier immer mit diá + Genitiv eingeleitet. Endlich folgt die eigentliche Aufforderung. Diese kann auf drei verschiedene Arten an das Vorhergehende angeschlossen werden: Durch Infinitivskonstruktion, durch einen Imperativ oder durch einen hína-Satz ${ }^{40}$.

Conviene observar que la frase que nos ocupa no reúne todas estas características. El mismo Bjierkelund hace notar que el sujeto, como es enfático, precede al verbo parakalô ${ }^{41}$. Esto hace que la conjunción dé no siga al verbo, sino que va detrás de la primera palabra, autós. Además, después de la expresión preposicional, sigue una oración de relativo que amplía el sujeto. Esta ampliación del sujeto aquí es comprensible, pues, al recoger la acusación co-

39. D.J. BJiERKelund, Parakalô. Form, Funktion und Sinn der Parakalô Sätze in den paulinischen Briefen. Oslo 1980. También N.A. DAHL, «Paul and the church at Corinth according to 1Corinthians 1,10-4,21»: Christian history and interpretation. Studies presented to J. Knox. Cambridge 1967, pp. 313-335, se ocupa someramente de estas frases en la p. 319 y remite a la aparición del libro de Bjierkelund.

40. Bjierkelund clasifica otros dos grupos de frases a las que llama también «parakalôSätze»: En el segundo grupo están 1Tes 4,1; 5,12-13; 2Tes 2,1-2. Estas frases no están introducidas por parakalô, pero muestran la construcción típica. El tercer grupo está representado por 2 Cor 2,8; 6,1; Gal 4,12; Fil 4,2-3; 1 Tes 5,27; Flm 9-12. Este grupo estaría emparentado con los otros dos, aunque las frases no presenten la construcción típica y no siempre están introducidas por parakalô. (Pp. 13-18).

41. Id., 191, nota 2 . 
rintia, prepara la oración de infinitivo, que responde a esta acusación. En cuanto a déomai, introducido también antes de la oración de infinitivo, habría que considerarlo como una continuación de parakalô, que, como veremos, refleja la situación crítica de Corinto. Podemos decir que, aunque no reúna todas las características, 2Cor 10,1-2 se ajusta básicamente al esquema formal de este primer grupo de frases. Por otra parte, las variaciones detectadas responden a la situación concreta en que Pablo escribe y serán de interés para nuestro trabajo.

Bjierkelund ha comprobado que estas frases corresponden a una forma presente en los escritores griegos y judíos del tiempo de Pablo, pero fundamentalmente en cartas, tanto privadas como oficiales, y en la diplomacia. No en el género parenético. Es de origen griego, pues no se encuentran paralelos hebreos.

Aunque Pablo utiliza parakalô con el significado de exhortar y consolar, no es éste el significado que tiene en las frases-parakalô. En ellas no es una orden, que se haría con el verbo epitásso - como el mismo Pablo precisa en Flm 8-10-, ni una súplica, que iría introducida por déomai ${ }^{42}$. Polibio distingue claramente entre parakalô//axiô y déomai ${ }^{43}$. Tras esta delimitación se ve que:

parakalô kommt dann bei Paulus zur Anwendung, wenn die Frage der Autorität kein Problem darstellen darf, und der Apostel sich an die Glieder der Gemeinde wie an seiner Brüder wenden kann, in dem Bewusstsein, das sie ihn als Apostel anerkennen wollen. Diese Aufforderung drückt also eine gewisse Zuversicht des Paulus gegenüber der betreffenden Gemeinde aus ${ }^{44}$.

$\mathrm{El}$ autor ha comprobado también que estas frases ocupan una posición fundamental en la composición de la carta. A menudo, la primera fraseparakalô de una carta introduce el propósito principal de Pablo, expresando lo que él quiere que los destinatarios hagan ${ }^{45}$.

Para nosotros es de gran interés que la utilización de estas frases suponga en Pablo la conciencia de que tiene autoridad para mandar, pero que, en lugar de hacerlo, pide una respuesta voluntaria.

Pero vengamos ahora a 2Cor 10,1-2. Esta frase-parakalô, como hemos visto, contiene algunas peculiaridades que son dignas de mención para nuestro objetivo. La frase empieza con el sujeto autòs dè egò Paûlos. Éste, que va ya expresado de una forma enfática (dos pronombres y un nombre), adquiere una dosis suplementaria de énfasis, pues varía el esquema habitual de las

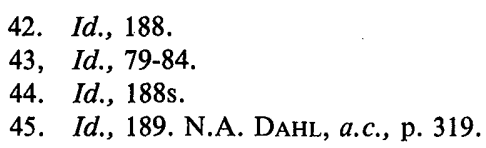


frases-parakalô. Es ya un indicio de que Pablo se hallaba en una situación especial, en la que la frase-parakalô no podía ser utilizada tan pacífica e incuestionadamente como en otras ocasiones. Lo confirma la aparición de déomai en el v. 2, inmediatamente después de la expresión preposicional. Este verbo debe ser considerado como una continuación de la frase-parakalô ${ }^{46}$. El cambio de parakalô a déomai, forma que Pablo utiliza también en la situación crítica de Gal 4,12, se explica si Pablo se daba cuenta que su autoridad en Corinto ya no era tan indiscutida ${ }^{47}$.

Pero, ¿qué aporta a nuestro tema la frase-parakalô de 2Cor 10,1-2? Que Pablo la utilice - aunque corrigiendo inmediatamente el parakalô con déomai- significa que no renuncia a su autoridad ni tampoco al modo en que ésta quiere ser ejercida, es decir, en el reconocimiento indiscutido y pacífico que le permita no ser autoritario. A ello se añade que con esta frase - la única frase-parakalô de 2Cor 10-13- Pablo introduce el objetivo principal de estos capítulos ${ }^{48}$. Y, si leemos, éste consiste en que los corintios se den cuenta de que está en ellos la posibilidad de que Pablo no deba comportarse con dureza, como piensa hacerlo si las cosas no cambian, es decir, si su autoridad no es reconocida como él quiere. Extraño modo éste de amenazar a gente que le está reprochando precisamente falta de decisión para afianzar su autoridad.

Está claro que detrás de las pretensiones de Pablo y de los reproches corintios hay dos compresiones distintas de autoridad. Así lo muestra la expresión preposicional, de la que todavía no hemos hablado. En un contexto en el que lo que está en juego es la fuerza de Pablo, como criterio para su autoridad, él exige cortésmente, apelando a la libertad de los corintios, más aún, suplica; que no le obliguen a ser osado y duro cuando los vea. Y lo hace dià tês praýtetos kaì epieikeías tou Christou («por la mansedumbre y benignidad de Cristo»). Frente a quienes en nombre de Cristo le reprochan falta de fuerza, él presenta una imagen de Cristo muy distinta a la que suponían esos reproches. Se trata, pues, de la contraposición de criterios diferentes, a los que Pablo les da una base cristológica ya desde el principio. Él se daba cuenta de esa diferencia de criterios y en toda la argumentación que va de 10,12 a 12,18 tratará

46. Cfr. E.-B. Allo, o.c., p. 243: «déomai, qui reprend sous un autre vocable l'idée de parakalô du v. 1, a certainement pur objet hymâs sous-entendu, et non Dieu (avec Plummer, Belser, Windisch, etc., et contre Rückert, B. Weiss, Bachmann)». Así también C.K. BARRETT, A Commentary..., p. 248.

47. D.J. BJIERKELUND, o.c., p. 155. El autor atribuye un peso fuerte para la aparición de parakalô en una situación tan crítica para el Apóstol a razones de estructura. Según él, las cartas de Pablo reflejarían una estructura eucharistô-parakalô (p. 189 y passim). No podemos ocuparnos de ello ahora, puesto que además en nuestro texto la cuestión se complica ulteriormente con los fortísimos problemas de crítica literaria que presentábamos al principio.

48. Cfr. supra. El versículo final del párrafo conclusivo $(13,10)$ lo confirma. 
de hacer que los corintios abandonen los criterios que están en la base de sus reproches.

b) 10,4b-6: logismoùs kathairoûntes kaì pân hýpsoma epairómenon katà tês gnóseos tou Theâ, kai aichmalotízontes pân nóma eis tèn hypakoèn tou Christou, kaì en hetoímoi échontes ekdikêsai pâsan parakoén, hótan plerothêi hymôn he hypakoé.

Nos encontramos al final del largo período de extensión de la amenaza inicial. Con kathairoantes comienza una serie de participios masculinos y que, por lo tanto, no concuerdan con hópla, neutro, sujeto del verbo anterior. Con Allo ${ }^{49}$, habría que relacionarlos con el sujeto de strateuómetha (v. 3).

Seguramente Pablo está aludiendo a características de sus adversarios ${ }^{50}$. Logismoús (pensamientos o planes) y nóema (pensamiento, proyecto) están utilizados en sentido peyorativo que nos aclara hýpsoma epairómenon. Hýpsoma es una palabra difícil de traducir. Aparece con un sentido diferente en Rom 8,39. Crisóstomo la traduce como altura fortificada, pero no se encuentra en griego este significado. Sea que se trate, como piensa probable Allo, de un término militar más de los que aparecen en estos versículos, con el sentido de alta muralla ${ }^{51}$, o que se remita uno simplemente, como hace Barrett, al participio que lo califica ${ }^{52}$, el sentido general es claro. Se trata de la altanería autosuficiente que no deja sitio a Dios de los que toman su propio pensamiento por criterio, sin confrontarlo con la voluntad de Dios (cfr. 10,12-18) ${ }^{53}$. Es dudoso si, en gnóseos toû Theoû, con gnóseos alude Pablo, como opina Allo, a algún conocimiento especial, en el sentido de doctrina, del que alardeaban sus contrincantes y que no coincidía con lo que decía Pablo ${ }^{54}$, o simplemente, como le parece más probable a Barrett, tendría un sentido equivalente al de epignósei en Rom 1,28 (tòn Theòn échein en epignósei) ${ }^{55}$. Puesto que esto no afecta mucho a nuestro trabajo, no nos entretenemos en dilucidarlo. En cualquier caso, es de interés subrayar que Pablo está defendiendo -así lo cree él por lo menos - la parte de Dios, no su propia parte, y ataca cualquier posición que ignore a Dios como instancia suprema.

En esta línea continúa el v. 5. La acción de Pablo va encaminada no a procurarse un grupo de gente sometida a él, sino a que haya obediencia a

49. E.-B. Allo, o.c., p. 244.

50. Cfr. C.K. Barrett, A Commentary..., p. 252.

51. E.-B. Allo, o.c., p. 244.

52. C.K. BARretT, $A$ Commentary..., p. 252.

53. Cfr. supra, lo dicho sobre katà sárka.

54. E.-B. Allo, o.c., p. 245.

55. C.K. BARret, $A$ Commentary..., p. 252. 
Cristo ${ }^{56}$. Se podría pensar que con ello está relativizando el problema de su propia persona. Pero en realidad está dando argumentos sobre la validez de su persona en cuanto apóstol. Pues lo que estaba puesto en cuestión era precisamente la capacidad que él tenía de mediar ese sometimiento a Dios. Nadie dudaba en teoría de que Dios era la instancia suprema. El problema era aducir los criterios que permitieran discernir quién era el apóstol que podía pretender la obediencia de los corintios en nombre de Dios. Pero hay que subrayar que, desde el primer momento, Pablo hace hincapié en que su interés principal es la persona de Cristo y no su persona.

Antes de pasar a otra expresión conviene hablar, en orden a obviar dificultades, del interrogante que plantea el v. 6. Con él surge el problema sobre a quién va dirigida realmente la amenaza de Pablo. Ahí dice que está preparado para vengar toda desobediencia cuando la obediencia de los corintios (hymôn) sea completa. Como dice Barrett, no se puede pensar que Pablo quisiera castigar a los corintios por su desobediencia pasada cuando sean obedientes. No sería el momento oportuno. Es más probable que cuando habla de vengar toda desobediencia tenga en mente a otra gente distinta de los corintios ${ }^{57}$. Habría que pensar en los oponentes de Pablo venidos de fuera (cfr. 10,12-18) ${ }^{58}$. Esto podría proporcionar la base para interpretar tínas del v. 2 como referencia a esta misma gente. Más claro sería todavía con tis y toûto del v. 7. Lo mismo podría decirse de phesín y toioûtos de 10-11. De todo ello se podría deducir que la amenaza de Pablo iba dirigida solamente a los foráneos y no a la comunidad. Sin embargo es curioso que la apelación vaya dirigida a la comunidad, como la que tiene en sus manos la decisión sobre si Pablo debe actuar severamente o no en la próxima visita. Además, en 12,19-13,10, párrafo conclusivo, se ve claramente que Pablo amenaza a la comunidad. Seguramente esta oscilación entre la comunidad y los intrusos como objeto de la amenaza haya que explicarla precisamente a partir del influjo que los intrusos estaban ejerciendo en la comunidad ${ }^{59}$. Muy probablemente era difícil para el mismo Pablo distinguir entre la acción de los intrusos y la participación de los miembros de la comunidad. Él podía darse cuenta de que la mayor parte de la comunidad era manipulada, pero también podía saber o suponer que los misioneros tenían sus adeptos-cabecillas en la misma comunidad, como lo prueba la situación de 1Cor 1-4.

56. En la expresión eis tèn hypakoèn tou Christoû, entendemos Christoa, por lo tanto, como genitivo objetivo. Ver en C.K. BarretT, $A$ Commentary..., p. 253, la discusión con Barth, que lo toma como genitivo objetivo y subjetivo al mismo tiempo.

57. Id., 253.

58. Id., 254.

59. Cfr. infra, sobre el trasfondo sociológico de la polémica entre los distintos misioneros. 
c) 10,7a: tà katà prósopon blépete

En esta frase el verbo podría ser entendido, bien como indicativo, bien como imperativo. Si se lo supone indicativo el sentido sería: «Miráis sólo lo que tenéis delante, la apariencia». Se trataría de un reproche que cuadra bastante bien a la situación y al contexto. El indicativo supondría que Pablo está haciendo una distinción explícita entre dos niveles, superficial y profundo, de observación de la realidad. Quizá demasido complicado. Con la mayoría de los autores preferimos considerar blépete como imperativo. El sentido sería: «Mirad lo que tenéis delante, es decir, la evidencia». Una traducción que no supone más que lo que dicen las palabras. Barrett recuerda que, aunque no sea decisivo, blépete es con frecuencia y característicamente empleado por Pablo en imperativo ${ }^{60}$.

Para lo que toca a nuestro interés, en cualquiera de las dos traducciones, lo que importa es que Pablo, en contraste con la amenaza, se sitúa en el terreno de la objetividad, de los criterios. Aunque esto se ve mucho más claro en la traducción aceptada. Como afirma Betz ${ }^{61}$, seguido por Barrett ${ }^{62}$, en Corinto, en aquella ocasión, se trataba de un problema de evidencia: «If the Corinthians will open their eyes and look, they will see that the situation is not as one-sided as they may have supposed $\gg{ }^{63}$. Estamos, pues, ante una frase con la que Pablo apela a la capacidad de ver de los destinatarios. No es una amenaza o advertencia, sino invitación, más o menos urgente, a la reflexión crítica, a afrontar el problema objetivamente, a dejarse interpelar por la realidad. Esta consideración objetiva de las cosas debe llevar a los corintios a la conclusión de que Pablo es de Cristo (v. 7b) y, por lo tanto, tiene autoridad apostólica (v. 8).

d) 10,8b: ...tês exousías hemôn, hês édoken ho kýrios eis oikodomèn kaì ouk eis kathaíresin hymôn

Esta expresión aparece casi textualmente igual al final, en $13,10 \mathrm{~b}$, y se puede considerar que hace inclusión. Cuando estudiemos el párrafo conclusivo aparecerá más claro su sentido. Pero ya ahora podemos decir algo sobre ella.

Se discute sobre la posibilidad de que Pablo esté haciendo alusión a Jer 1,$10 ; 24,6$. Hay opiniones en pro y en contra ${ }^{64}$.

60. C.K. BARrett, A Commentary..., p. 256.

61. H.D. BETZ, o.c., pp. 132-137.

62. C.K. Barrett, A Commentary..., p. 256.

63. Id., 256.

64. Cfr. J. HAINZ, Ekklesia. Strukturen paulinischer Gemeinde-Theologie und GemeindeOrdnung. Regensburg 1972, p. 162, nota 7. 
El problema de la conexión entre los vv. 8 y 9 ha ocupado mucho la atención de los exegetas. Es realmente un problema difícil. Barrett considera las distintas posibilidades de que hína mé esté conectado con alguna palabra en particular del v. 8. El resultado es negativo ${ }^{65}$. Antiguos comentadores, como también la Vulgata y Loisy, relacionan el v. 9 con el v. 11, haciendo del v. 10 un paréntesis. Para lo cual suponen un punto delante de hína mé. Contra esto afirma con acierto Allo que en tal caso tendría que haber después de hína mé un dé u otra partícula, pues si no sería una asíndesis poco natural. De hecho, el traductor de la Vulgata ha introducido autem ${ }^{66}$. Windisch piensa que habría caído un principio de frase antes de hína mé, lo que Héring llama «une solution de désespoir» ${ }^{67}$. J. Weiss piensa que nuestra frase sería una interpolación tomada de 13,10 , lo que va contra todos los manuscritos y olvida que $10,8 \mathrm{~b}$ y $13,10 \mathrm{~b}$ no son una repetición ${ }^{68}$. Lo mejor es rendirse a la evidencia de una conexión irregular, que no debe extrañar demasiado en el estilo de Pablo $\mathrm{y}$ en una situación emocionalmente fuerte ${ }^{69}$. Con Allo podemos decir «que le v. 8, pour l'idée, dépend comme un tout du précédent, sans qu'on puisse le rattacher grammaticalement à aucun mot particulier» ${ }^{70}$. Pero esto no nos exime de preguntarnos por el sentido de esta dependencia. Bachmann, seguido por Héring, es quien nos puede dar la solución. Deja la coma entre los vv. 8 y 9, pero supone un tácito «solamente» delante de ekphobeîn, restricción ésta que no es siempre explícita en griego. En nuestro caso hace perfectamente justicia al texto. «Paul ne veut pas avoir l'air de tirer des coups en l'air, simplement 'pour faire peur'. La particule hosàn= quasiment semble confirmer cette interprétation" ${ }^{71}$. Así se explica el tenor tanto de los versículos precedentes como de los siguientes y $8 \mathrm{~b}$ tiene también una función en el texto.

En el v. 7 Pablo ha dicho que él también es de Cristo. Con ello le ha parecido empezar a gloriarse. Por lo que añade (v. 8) que, aunque se gloriase más todavía (perissóterón ti) sobre su autoridad, no quedará avergonzado. Con ello está adelantando la amenaza del v. 11, es decir, se está refiriendo a la objetividad de su autoridad, que, de hecho, puede actuar con fuerza. Con $8 \mathrm{~b} \mathrm{~Pa}-$ blo cualifica, en un paréntesis, su autoridad. Es una autoridad que Dios le ha dado para la edificación - metáfora común en Pablo ${ }^{72}$ - y no para la des-

65. C.K. BARRETT, A Commentary..., pp. 258s.

66. E.-B. Allo, o.c., p. 248. Lo mismo piensa J. Hering, La seconde épître de Saint Paul aux Corinthiens. Neuchâtel 1958, p. 80.

67. J. HERING, o.c., p. 80.

68. Cfr. E.-B. Allo, o.c., p. 247.

69. Id., 248. C.K. BARRETT, A Commentary..., p. 259.

70. E.-B. Allo, o.c., p. 247.

71. J. HERING, o.c., p. 80.

72. Cfr. C.K. Barrett, A Commentary..., p. 258. 
trucción de la comunidad. El estudio de 10,1-2 nos ha hecho ver cómo con las frases-parakalô Pablo quería que su autoridad fuese reconocida; de forma que no tuviera que ejercerla mediante una intervención dura. El modo en que Pablo quiere ejercer su autoridad es en la paz del reconocimiento y no en la imposición violenta. Sólo en el primero la edificación es segura, mientras que en el segundo hay un fuerte riesgo de destrucción ${ }^{73}$. En 13,10 Pablo cualifica su autoridad con las mismas palabras que lo ha hecho en 10,8b. Pero en 13,10, antes de chrésomai, introduce el adverbio apotómos («severamente»). Es una cualificación de la ejecución de su autoridad ${ }^{73 a}$. Lo que Pablo trata de evitar, por lo tanto, no es poner en acto su autoridad, como quiere Hainz ${ }^{74}$, sino ponerla en acto severamente. Pablo querría - generalicemos como hipótesis de trabajo- que sus intervenciones de autoridad con respecto a la comunidad pudieran ser siempre formuladas con una frase-parakalô en su forma pura, que supone comunidades en las que la autoridad de Pablo es indiscutida. En ellas la autoridad se ejerce renunciando a la imposición, porque es aceptada en libertad. Pero se ejerce.

La expresión de $10,8 b$, en un contexto donde Pablo afirma la objetividad de la autoridad que posee, cualifica esta autoridad. Pero la cualificación no es independiente del modo en que la autoridad se ejecuta. El modo en que Pablo la ha ejercido hasta ahora, en contraste con los intrusos, es un tanto paradójico. Hasta el punto de que a los corintios les ha llegado a parecer que no la tenía y que sólo aparentemente, sin dar la cara, es capaz de mostrarse osado. La forma de proceder de Pablo ha inducido a confusión a gente que está acostumbrada a otro tipo de evidencia. Por eso él tiene cuidado de cualificar su autoridad como dada por Dios para la edificación y no para la destrucción. Esa cualidad de su autoridad - cosa que sus oponentes no podrían decir- explica su comportamiento respetuoso y no prepotente para con los corintios. Estamos, pues, de nuevo ante una diferencia de criterios sobre la autoridad.

\section{Conclusiones}

En las conclusiones a 1 constatábamos ya lo difícil que era conjugar en una propuesta coherente para la comunidad los distintos aspectos de la actitud de Pablo en su interpelación a los corintios. Esta dificultad queda confirmada con la continuación del estudio. Hemos visto que a Pablo le importa mantener su autoridad en Corinto, pero quiere que sea reconocida según sus criterios, o

73. Cfr. supra.

73a. Esto supone que en 13,10 katò tèn exousían... cae también bajo el efecto negativo de mé. Cfr. infra.

74. J. HAINZ, o.c., p. 163. 
sea, en la paz de la evidencia indiscutida, según razones objetivas, como una autoridad que no necesita imponerse por la fuerza, en la cual no importa su persona por sí misma, sino en cuanto es objetivamente capaz de mediar la obediencia a Cristo. A los corintios se les pide que consideren la evidencia, lo que implica confrontar los criterios sobre la autoridad que dan soporte a las acusaciones contra Pablo con otro modelo de autoridad, basado en un Cristo manso y benigno. Pero lo curioso es que Pablo haga esto amenazando con una visita severa: si los corintios no responden a la propuesta, se hará presente con osadía. El objetivo de la carta parece ser evitar tener que recurrir a ello. Si esta osadía debe entenderse como un cambio de táctica por parte de Pablo, no nos queda más remedio que concluir que la formulación del objetivo de la carta contradice la formulación de la respuesta que Pablo esperaba de los corintios. Si éstos no se convencían por las buenas, único modo en que puede haber una convicción, ¿qué sentido tenía ya una intervención dura, en la que el reconocimiento de su autoridad no se haría según sus criterios, sino según el modelo de sus oponentes? Pablo se podía cotradecir. Pero antes de llegar a esa conclusión debemos considerar la posibilidad de que detrás de su amenaza haya algo distinto a un simple cambio de método para ganarse adeptos. ¿Era posible un ultimatum sin cotradecirse? El párrafo conclusivo nos dará ocasión de contestar a esta pregunta.

Por el momento hay algo claro: Pablo esperaba que los corintios se pusieran de su parte y reconocieran su autoridad y que hicieran esto valorando la autoridad con criterios distintos a los de los intrusos, que no eran objetivos. Sin embargo, detenerse ahí sería olvidar lo problemática que una propuesta tal se presentaba para una comunidad en conflicto entre dos ofertas distintas y los interrogantes que plantea sobre las pretensiones de Pablo. El hecho de que no consigamos encajar la amenaza en tal propuesta es también una confirmación de ello. El análisis de 12,19-13,10 nos permitirá profundizar en el problema y acercarnos a las conclusiones.

\section{2 CoR $12,19-13,10$}

A partir de 12,19 Pablo deja los argumentos en torno a cosas concretas sobre su comportamiento y el de sus oponentes. Vuelve la vista reflexivamente hacia lo que ha estado diciendo y aclara su posición frente a los corintios.

Aparecen de nuevo expresiones parecidas a las de párrafo inicial: Pablo está preocupado por la edificación de la comunidad $(12,19 ; 13,10)$; anuncia claramente su visita y teme tener que comportarse en ella duramente, aunque lo hará si se ve obligado $(12,20-13,2 ; 13,9-10)$; escribe precisamente para evitar una visita severa $(13,2.10)$. 
Se podría calificar este párrafo como de aclaración, conclusión y exhortación.

\section{Análisis}

a) 12,19

Pablo conocía a los conrintios ${ }^{75}$. Seguramente ya hacía tiempo (pálai) ${ }^{76}$ estaban pensando que se defendía ante ellos. Si se trata de una pregunta o una afirmación, no es fácil decidirlo. En cualquier caso, aparece clara la intención de Pablo de negarlo. En realidad, no sólo los corintios, sino cualquiera que leyera los párrafos anteriores, podía pensar que Pablo se estaba defendiendo. Él quiere salir al paso de un posible malentendido a este respecto, afirmando categóricamente que está hablando «delante de Dios, en Cristo», expresión literalmente igual a la de 2,17 . También allí está proponiendo la excelencia de su ministerio, en contraste con el de otros $(2,17 a)$ y también allí trata de aclarar que no necesita recomendaciones para con los corintios, como hacen otros $(3,1 \mathrm{ss})$. En 12,19a a Pablo le interesa dejar claro que no se trata de salvar su propia reputación, de una defensa ante los hombres (ante la comunidad), que lógicamente debería ser hecha por criterios humanos y llevaría a una autorrecomendación, no a una recomendación del Señor (cfr. 10,12.18). Se trata de ajustarse a los criterios de Dios, de hablar ante Dios en Cristo (en Christôi), es decir, con una existencia motivada y basada en Cristo ${ }^{77}$.

No es la primera vez que Pablo se esfuerza en hacer ver a los corintios que no le importan las opiniones o juicios que su persona les pueda merecer. Ya en 1 Cor 4,3-5, en una situación parecida, en que el apostolado de Pablo era comparado con el de otros misioneros, él trata de hacer ver que su misión es independiente de lo que los hombres piensen de ella, él es juzgado sólo por Dios. Que Pablo no se expresaba así sólo con la comunidad de Corinto lo prueban Gal 1,10 y 1 Tes 2,6 .

Pablo habla, pues, ante Dios en Cristo y todo lo que hace es por la edificación de la comunidad (v. 19b). A él le interesa la cuestión objetiva de que los corintios sean como tienen que ser, no la gloria personal ${ }^{78}$. Si ha hecho el loco, hablando de un modo que no le gustaba, que no responde aparentemente a

75. Cfr. C.K. BARretT, A Commentary..., p. 328.

76. $\mathrm{p}^{46}$ lee ou delante de palai, seguramente preguntando. $\mathrm{S}^{2} \mathrm{D} 044 \mathrm{M} \mathrm{g} \mathrm{vg}{ }^{\mathrm{mss}}$ y bo tienen palin en vez de palai. Cfr. C.K. BARRETT, $A$ Commentary..., p. 326: «the latter variant is probably an assimilation to 3,$1 ; 5,12$; the $o u$ in $\mathrm{p}^{46}$ may have come from 5,12 ).

77. Id., pp. $105,328$.

78. Cf. infra. 
esa pretensión de dar razones sólo a Dios y dejar hablar simplemente a su existencia en Cristo, es por la edificación de la comunidad. Lo cual supone que, en la opinión de Pablo, la edificación de la comunidad pasaba por la aceptación por parte de los corintios de Pablo como apóstol. Pero esto necesita ulterior precisión, a la que nos llevarán los versículos siguientes.

b) $12,20-21$

Si Pablo está escribiendo como lo hace es porque (gár) teme (phoboûmai) que en su visita a Corinto ocurran cosas aciagas. De phoboûmai dependen tres frases, introducidas por mé pos (las dos primeras) y mé (la tercera), que expresan el objeto del temor de Pablo.

¿Qué es lo que teme realmente en la primera (mé pos elthòn ouch hoíous thélo heúro hymâs kagò heurethô hymîn hoîon ou thélete)? Lo más sencillo sería suponer, como es habitual, que Pablo está expresando en forma de temor lo que en el primer párrafo y también en 13,2 es un aviso o una amenaza abierta. Digámoslo con palabras de Barrett:

The undesirable qualities Paul fears he may find in the Corinthians are listed, or at least illustrated, in the next sentence. Where he himself is concerned, his fear is presumably that he may have to visit Corinth not in love and a spirit of gentleness, but with a rod (cf. 1Cor 4,21). He goes on to promise that on his next visit he will not spare them $(13,2)$; he will be in person at least as firm as he is by letter $(10,11)$. He has a positive authority to exercise in Corinth $(10,8$; 13,10 ), and his behaviour will not conform to Coronthian requirements ${ }^{79}$.

Así pues, según esta opinión kagó heurethô hymîn hoîon ou thélete aludiría a la reacción dura de Pablo cuando vea que los corintios persisten en la conducta desagradable a sus ojos. Sin embargo Barrett olvida que en el versículo siguiente (v. 21) Pablo está temiendo ser humillado en Corinto y que en ninguna de las oraciones dependientes de phoboûmai hay alguna expresión que aluda a la severidad de que Pablo piensa hacer uso en su visita si los corintios no se corrigen. El rostro de Pablo en estos dos versículos es el de una persona que teme y que ante una situación desastrosa acude al luto, al lamento (penthéso). Además - aunque no se pueda urgir mucho este argumento-, en cierto modo, ¿no querían los corintios ver a Pablo enfadado? Éste parece reflejar en 11,20 que la comunidad se siente más contenta con apóstoles impositivos. Seguramente si él «jugara» a hacerse el enfadado sería más accesible a los criterios de los corintios. Es un dato más que, en nuestra opinión, hace improbable que Pablo se esté refiriendo con esta expresión a la posibilidad de usar de

79. C.K. Barrett, A Commentary..., p. 329. 
severidad en su visita. Nuestra interpretación de la afirmación paulina se limita a las últimas palabras de la cita de Barrett: «... his behaviour will not conform to Corinthian requirements». Lo mismo que los corintios no se ajustarán a los criterios de Pablo, tampoco éste se ajustará a los de ellos, pues no puede ceder en lo que cree fundamental. Está aludiendo, pues, a un posible mutuo rechazo, que podría suponer de hecho una humillación para el Apóstol.

La segunda oración dependiente de phoboûmai introducida por mé pos especifica con una serie de sustantivos el estado de cosas propio de una situación que sería ocasionada por la irrupción de apóstoles rivales, donde unos están de un lado y otros de otro ${ }^{80}$ : discordia ${ }^{81}$, envidia ${ }^{82}$, arrebatos de ira, intrigas, difamaciones, murmuraciones, engreimientos, alborotos.

La tercera frase presenta un problema gramatical insoluble ${ }^{83}$. ¿Con qué verbo va pálin, con elthóntos o con tapeinósei? Ambas cosas son gramaticalmente posibles. En favor de la primera habla la cercanía en el texto. La segunda está apoyada por el hecho de que tapeinósei es el verbo principal y el genitivo absoluto elthóntos mou se podría considerar una especie de paréntesis. También desde el punto de vista de la historia ambas posibilidades son válidas. Pablo ya había estado en Corinto antes, pues ésta sería la tercera visita $(12,14 ; 13,1)$. También había pasado allí por una situación humillante (cfr. $7,12)$. Así pues, pálin podría ir con cualquiera de los dos verbos. Sólo hay un indicio, apuntado por Allo, que sigue a su vez a Plummer, en favor de la relación de pálin con tapeinósei. Pablo podría haber puesto este pálin delante de elthón, en el versículo precedente, si quisiera hacer ver que tenía previsto ir otra vez ${ }^{84}$. Pero tampoco este argumento es del todo convincente, pues no se hacen todos esos razonamientos cuando se está escribiendo una carta. Pero de todas formas hace esta segunda posibilidad más probable.

Pablo habla de una posible humillación. Humillación que en el caso de su misión habría que entender como fracaso ${ }^{85}$ y que podemos comprender mejor a la luz de lo dicho sobre la primera frase dependiente de phoboûmai. Pablo, que no está dispuesto a ceder, no sería aceptado en la comunidad. Estos dos versículos suenan a impotencia y miedo y contrastan con las expresiones de

80. Cfr. C.K. BARretT, «Paul's opponents...», p. 247.

81. B D F G $044 \mathrm{M}$ latt sy ${ }^{\mathrm{h}}$ co leen ereis, en plural, problablemente por asimilación con los demás plurales de la lista.

82. S D ${ }^{1} 0440243 \mathrm{M}$ latt sy ${ }^{\mathrm{h}}$ co tienen zeloi, seguramente por la misma razón que la palabra anterior.

83. Cfr. C.K. Barrett, A Commentary..., p. 330.

84. E.-B. Allo, o.c., pp. 334, 335.

85. Cfr. C.K. BARrett, A Commentary..., p. 331: «Humiliation was a failure». 
amenaza del primer párrafo y las que siguen inmediatamente. Quizá contribuyan a esclarecer hasta qué punto consideraba Pablo «extrema», a la desesperada, una intervención dura. Tal intervención sólo podía venir como consecuencia de un fracaso, no era concebida como un procedimiento normal. Ésta sería una diferencia importante entre Pablo y los intrusos. Si Pablo actuaba con severidad, sería porque ya no había posibilidad de hablar, no porque pusiera por obra una nueva táctica.

En cualquier caso, como muy bien nota Barrett, el sujeto de esa humillación es Dios, no los corintios. Si una cosa tal ocurría, sería porque Dios lo permitía, lo mismo que era Dios quien le había puesto el aguijón en la carne $(12,7){ }^{86}$. Además, estaría en pleno acuerdo con la debilidad que constituye la gloria y la fuerza $(11,30 ; 12,6.9-10)$, que en $13,3-4$, como veremos, Pablo fundamenta cristológicamente.

Pablo dice que tendrá que guardar luto por muchos que, habiendo pecado antes, no se han convertido ${ }^{87}$. Los pecados enumerados ahora son: impureza, fornicación y libertinaje. Estos son pecados de inmoralidad sexual y no de rivalidad, como nota bien Barrett citando a Georgi ${ }^{88}$. Los autores lo suelen relacionar con las tendencias libertinas que Pablo se vio obligado a corregir en 1Cor. Éstas no habrían pasado del todo y el Apóstol, además de la situación de contienda y división, tendría que enfrentarse también con viejos pecadores (proemartekótes) cuando vaya ${ }^{89}$. Pero la pregunta que se plantea es si existe una relación entre la situación de división en torno a distintos misioneros, cuyas consecuencias se verían reflejadas en los pecados del v. 20 , y estos pecados de libertinaje. La posibilidad de detectar esta relación la encontramos quizá en el estudio sociológico de Theissen ${ }^{90}$. Los orígenes de las contiendas entre las distintas facciones de 1Cor 1-4 habría que localizarlos sociológicamente entre las personas que tenían medios para alojar y sustentar a los misioneros ${ }^{91}$, es decir, entre los pocos sabios, poderosos y nobles $(1$ Cor 1,26$)$ de la comunidad. Éstos eran los que disponían de casas para albergar también a la comunidad y ejercían influjo sobre sus propios grupos, convirtiendo una cuestión de pocos en una cuestión de muchos. Éstos eran los únicos que tenían igualmente acceso a la formación y a la cultura, con posibilidad de viajar, lo que los hacía

86. Id., 330s.

87. Sobre los participios, proemartekóton y metanoesánton, cfr. Id., 332: «The participles are in the genitive case, wrongly; Paul does not mean (as his words strictly taken would imply) that there would be some unrepentant sinners over whom he would not mouRn».

88. Id., 332.

89. Cfr. C.K. BarretT, «Paul's opponents...», pp. 247s. E.-B. Allo, o.c., p. 334.

90. G. THEISSEN, o.c., pp. 54-57, 96-99.

91. Id., pp. 54s: «Naturally, nobody wishes to spend money for a second class missionary». 
abiertos a ideologías paganas liberales, en ambientes donde se respiraba la gnosis. Esto explicaría sociológicamente el largo espacio que ocupa en 1Cor 1-4 la corrección del énfasis puesto por algunos en la ciencia y que Pablo tenga que vérselas con una ideología liberal y culta en otros lugares. La estructura del conflicto es básicamente la misma en 2 Cor 10-13:

In 2 Corinthians we hear nothing more about this strife among parties. Instead, almost all the Corinthians now seem united in a position opposing Paul. In its structure, however, this new conflict is comparable tho the old. The attitude opposing Paul results from the respect now being accorded to the newly arrived «superlative apostles». These apostles are scarcely likely to have found shelter with those Christians who showed up at the Lord's Supper with «nothing» (1Cor $11,17 \mathrm{ss})$. Nor are those attracted to them the least cultured of people. They can evaluate letters, and they raise certain objections to Paul's appearance and rhetoric. Paul responds with arguments employing a clutch of allusions drawn from popular philosophy, which not everybody would have understood ${ }^{92}$.

Así pues, tampoco es la primera vez que los pecados de libertinaje aparecen asociados en la correspondencia corintia a las contiendas y divisiones. Había una base sociológica real. El v. 21, por consiguiente, podía surgir de la pluma de Pablo después del 20 sin hacer ningún salto, sin pensar en «nuevos» viejos problemas. Se explica que en una situación de rivalidad, en la que los pocos sabios, poderosos y nobles tenían un papel clave, hubiera gente que se viera ya desde antes y sin perspectivas de arrepentimiento en un tipo de vida libertino.

Esta reflexión, además, nos permite apreciar más en vivo las repercusiones comunitarias del influjo de uno $u$ otro apóstol, canalizado a través de una compleja interacción social, en la que, como ya se dijo ${ }^{93}$, era difícil saber dónde terminaba lo de fuera y empezaba lo de dentro. Éste es el escenario donde Pablo combate por mantener su autoridad. Algo que se le estaba poniendo muy difícil, teniendo en cuenta su actitud intransigente, por ejemplo, en cuanto a aceptar ayuda económica de los corintios (cfr. 11,9b-10; 12,14-15). ¿Qué posibilidades de captarse adeptos tenía alguien que rechazaba las tácticas habituales de influir, como podía ser en Corinto aceptar manutención de ciertas personas que después apoyarían su candidatura?

92. Id., 57. Esto apoyaría también lo que dice Barrett sobre la adaptación de los intrusos al medio. Cfr. supra, nota 12.

93. Cfr. supra, comentario a 10,6 . 
c) $13,1-2$

Pablo repite que piensa ir por tercera vez a Corinto (Cfr. 12,14). El tono de su discurso cambia. Recobra la firmeza y el carácter amenazante. Pablo advierte con toda contundencia, incluso utilizando un lenguaje legal: epi stómatos dýo martýron kai triôn stathésetai pân rêma $(13,1 \mathrm{~b})$. Es una cita de Deut 19,15 (cfr. Mt 18,16). Desde Crisóstomo hasta un gran número de comentaristas modernos, entre los cuales están Plummer, Bachmann, Windisch y Héring, han interpretado el uso de esta cita por el Apóstol en el sentido de que tres visitas hechas por una persona, es decir, por él, en distintos momentos, pueden ser consideradas como tres testigos ${ }^{94}$. Contra ellos Allo, entre otros ${ }^{95}$, toma la expresión literalmente, o sea, Pablo estaría decidido a llevar a cabo un juicio con los requisitos legales del Deuteronomio. En la línea de la primera opinión parece sugerente y aceptable la opinión de $\mathrm{H}$. van Vliet, seguida por Barrett: Pablo citaría Deut 19,15 a la manera de un proverbio, lo que probaría que era una regla viviente en su mente. La idea de testimonio se habría desarrollado y empleado en el sentido de avisos, advertencias. Sus visitas lo habían sido. Pablo vendría a decir: «Ya habéis tenido suficientes advertencias, como está prescrito. Ahora el caso está maduro para la decisión» ${ }^{96}$.

Apoya esta interpretación la aparición del término «advertir» (proeíreka kai prolégo) ${ }^{97}$ en el v. 2. Pablo está decidido a actuar con firmeza. Ya se lo había advertido presente en la segunda visita y lo advierte de nuevo ahora: «si voy de nuevo ${ }^{98}$ ou pheísomai». Ésta era la razón por la que Pablo no había vuelto por Corinto: hoti pheidómenos hymôn oukéti êlthon eis Kórinthon (2Cor 1,23b). Pheídomai significa originalmente perdonarle a uno la vida en una batalla. Por extensión, especialmente en los LXX, ha venido a significar tener misericordia de alguien, tratarlo con miramiento ${ }^{99}$.

Es el momento de aventurar una respuesta al interrogante sobre la amenaza de Pablo. ¿Cuál era su contenido real? Barrett piensa que lo que Pablo no había hecho todavía (2Cor 1,23 ), pero ahora estaría dispuesto a hacer, se puede entender sólo a la luz de 1 Cor 5,5, donde ordena que el incestuoso sea

94. J. HÉRING, o.c., p. 101.

95. E.-B. Allo, o.c., p. 335.

96. C.K. BARRETT, A Commentary..., p. 333.

97. Para la traducción de prolégein nos basamos en H.G. LidDEL-R. ScotT, $A$ GreekEnglish Lexicon. Oxford 1958, p. 1488, s. v., 3, seguido por C.K. BARRETT, A Commentary..., p. 333s: «The verb Paul uses hier (prolégein), though it may bear the simple meaning 'to say beforehand', 'to tell in advance', is best taken to mean 'to warn'... 'I have told you in advance and am now telling you in advance' is not impossible but somewhat heavy-handed".

98. Eis tò pálin puede ir con éltho o con ou pheísomai. Con la mayoría de los autores, aceptamos la primera posibilidad.

99. Cfr. C.K. BarretT, A Commentary..., p. 334. 
expulsado de la comunidad. Sólo que en la situación de 2Cor 10-13 Pablo corría el riesgo de ser expulsado él si convocaba una reunión de la comunidad:

Paul had in fact no weapon at all except the truth, the Gospel applied to the situation. As he had proclaimed in Corinth the good news constituted by the word of the Cross (1Cor 1,$18 ; 2,2)$, so he could now declare that those who by word and deed were denying the Gospel had thereby alienated themselves from the merciful God and had fallen back into the realm of Satan. This is neither excomunication nor a curse, but an unrelenting faithfulness to the truth of the mercy in which alone God will deal with men (Rom 11,30ss). Paul must have known that his faithfulness might (humanly speaking) destroy him, and the church on which he had bestowed so much love and labour; there was however no alternative ${ }^{100}$.

La opinión de Barret nos ofrece una buena pista, coherente con todos nuestros hallazgos. Hemos visto que Pablo no se arrepiente de su comportámiento respetuoso, la idea que tenía de cómo debía ser reconocida su autoridad - no quería ser un tirano de la fe de los corintios $(2$ Cor 1,24$)$-, que pensaba que la mediación del apóstol no debía ser impositiva. En la parte central de nuestros capítulos, sobre todo en el discurso en locura $(11,16-12,10)$, ha tratado de mostrar que el único verificante de la validez del apóstol es la experiencia radical de Cristo que comunica. El prestigio de origen, la exhibición de méritos, las visiones... no son verificantes válidos, pueden encubrir orgullo, falsa seguridad, obediencia al apóstol antes que a Cristo y, en consecuencia, degradación de la mediación y con ella de la experiencia cristiana ${ }^{101}$. Los corintios no quieren una mediación libre del apóstol, sino alguien que los contente, que responda a sus necesidades de seguridad. Pablo ha dicho que podría hacerlo, que goza, incluso en mayor medida que los misioneros intrusos, de los requisitos para esa falsa dokimé ${ }^{102}$, pero que prefiere mostrarse débil, en vez de alardear de una fuerza que es sólo humana, demasiado humana. Hemos visto además el temor real de Pablo a ser rechazado por la comunidad, a ser humillado en Corinto. Todo ello es evidencia suficiente para concluir que este no pheídesthai de Pablo en la visita próxima no podría consistir en utilizar el enfado como táctica represiva para amedrentar, lo que lo situaría al mismo nivel de sus oponentes. Esta visita severa solamente podía ser un último testimonio, pero ya sin contemplaciones - en este sentido se puede hablar de cambio en la actitud de Pablo, pero cambio coherente- de la propia experiencia

100. Id., 334 .

101. Cfr. E. KAESEMANN, a.c., p. 48: «Wir wagen nunmehr die Behauptung, dass Paulus eben in der Bestreitung seines Apostolates eine Verfälschung des Evangeliums wahrnahm».

102. Sobre esta palabra cfr. infra. 
cristiana, rompiendo con quien fuera preciso romper, aunque fuese toda la comunidad. Sería un actuar con autoridad que, como dice Barrett, podía destruirlo y destruir. Pero también, en caso de recalcitrancia, la única posibilidad de que los corintios tuviesen la prueba de la «fuerza» que Dios da a un apóstol para afrontar si es preciso la destrucción, realizando así la experiencia de Cristo. Esto nos lleva a los versículos siguientes.

\section{d) $13,3-4$}

Pablo tendría que actuar así, puesto que (epeí) los corintios siguen buscando una prueba (dokimén) «del Cristo que habla en él» (toû en emoì laloûntos Christô̂) (3a). Los vv. 3b-4 están construidos en torno a la debilidad y la fuerza de Cristo como experiencia repetida por el Apóstol. La fuerza de Pablo había sido puesta en duda en base a criterios sensacionalistas. Y con ella se dudaba de que Cristo hablara en él. Pablo argumenta ahora sobre la naturaleza de su fuerza, que está basada en la de Cristo. Éste es el momento oportuno para hacerlo, pues en los versículos precedentes estaba amenazando con una intervención excepcionalmente severa, que, aunque humanamente hablando le pudiera salir mal -o quizá precisamente por eso-, requería una fuerza fuera de lo común.

Pablo comienza afirmando que el Cristo que habla en él (hós) «no es débil para con vosotros, sino que es fuerte en vosotros» (3b). Esto lo podían apreciar ya los corintios a partir de los frutos de la actividad de Pablo ${ }^{103}$. Sin embargo esta evidencia no era tan evidente para ellos. De hecho se había puesto en duda al compararla con la actividad de otros misioneros. Por eso Pablo ahora, al final de la carta, cuando amenaza con una intervención de fuerza, que quiere evitar, se ve obligado a argumentar sobre su propia fuerza comparándola con la de Cristo, cuya fuerza los corintios no podían negar.

Pero también en esta ocasión recuerda aspectos del misterio de Cristo que parecen no tener en cuenta quienes minusvaloran la actividad del Apóstol aplicándole criterios sensacionalistas. Pues Cristo «fue crucificado por debilidad, pero vive por la fuerza de Dios» (3b). Ya en 1Cor 1,17-18 Pablo tuvo que oponer la palabra de la cruz a la primacía que se daba en la predicación de los apóstoles a la sabiduría del discurso (sophíai lógou), que podía vaciar la cruz de Cristo. De nuevo ahora recuerda a los corintios que están creyendo en alguien que murió crucificado. Y fue crucificado por debilidad (ex astheneías). La clave para entender la debilidad de Cristo nos la da el contexto. La raíz aparece 14 veces en 2 Cor 10-13. En 12,9-10, como colofón a la noticia sobre el

103. Cfr. C.K. Barrett, A Commentary..., p. 335. 
«aguijón en la carne», cuatro veces, emparejada paradójicamente con dýnamis: la fuerza de Pablo se cumple en la debilidad, cuando es débil entonces es fuerte, por eso se gloría en sus debilidades (así también: 11,30; 12,6). Evidentemente en todos estos casos asthéneia se refiere a lo que no responde a los juicios sensacionalistas de los corintios y dýnamis a la acción poderosa de Dios a través de esa aparente insignificancia humana ${ }^{104}$. Pero es claro que esta fuerza de Dios no es sólo algo que se manifiesta a posteriori confirmando de un modo sensacionalista la validez amenazada del Apóstol, sino que es evidente ya para quien sabe apreciar la fuerza necesaria para no sucumbir al sensacionalismo. El intento de Pablo en esta carta es precisamente convencer de eso a los corintios. En este sentido habría que interpretar también la debilidad por la que Cristo murió crucificado. Aunque no haya dependencia literaria, las burlas a Jesús en la cruz (Mc 15,29-32) interpretan bien el sentido de esta debilidad, pues reflejan una mentalidad sensacionalista, que no sabe distinguir la verdadera fuerza.

Los corintios tenían necesidad de que se les dijera esto, aun cuando Pablo les estaba hablando de que tenía fuerza suficiente para ir sin contemplaciones a Corinto. En efecto, el énfasis aquí es puesto en el segundo miembro de la afirmación: «pero vive por la fuerza de Dios». En Cristo crucificado por debilidad Dios ha actuado con fuerza, haciéndolo vivir. La resurrección es el otro aspecto del misterio de Cristo, en el que la fuerza de Dios se ha manifestado. Pero, como hemos visto, es una fuerza ya presente en su muerte débil, una fuerza que capacita para afrontar la debilidad y la muerte.

Por todo esto Pablo sabe que está repitiendo la experiencia de Cristo: kaì gàr ${ }^{105}$ hemeîs asthenoûmen en autôi ${ }^{106}$ allà zésomen sỳn autôi ${ }^{107}$ ek dynámeos Theoû eis hymâs ${ }^{108}$ (v. 4). Esa visita en la que Pablo tendría que actuar sin miramiento sería realmente una manifestación de la fuerza de Dios en Cristo resucitado. Se trata de la fuerza que Dios da al Apóstol para tratar con una situación comprometida de la comunidad (eis hymâs). Pablo, cuya presencia habitualmente es débil è insignificante, puesto que no apoya lo que pro-

104. Así aparece claramente en la respuesta de Dios en 12,9.

105. Nótese que lo que se dice de Cristo y del apóstol es introducido igualmente por kai gár, lo cual refuerza el paralelismo y el efecto de repetición.

106. S A F G pc r sy ${ }^{\mathrm{p}}$ bo leen syn en vez de en. Según la opinión de B.M. MetzGer, A textual commentary on The Greek New Testament. London/New York 1975, pp. 587s. y C.K. BARRET, $\boldsymbol{A}$ Commentary..., p. 327, se debería a asimilación con syn de zesomen syn autoi que sigue inmediatamente.

107. Por una asimilación inversa a la ocurrida con en antes, $\mathrm{p}^{46 \mathrm{vid}} \mathrm{D}^{*} 33326 \mathrm{pc}(\mathrm{g}) \mathrm{Pel}{ }^{\mathrm{pt}}$ leen ahora en en vez de syn. Cfr. B.M. METzGer, o.c., p. 588 y especialmente C.K. BARRETT, $A$ Commentary..., pp. 327, 337.

108. eis hymas faltà en $\mathrm{B} \mathrm{D}^{2} \mathrm{r}$. 
pone con fuerza humana, tendrá sin embargo la fuerza para enfrentarse a una comunidad endurecida sin ceder en sus principíos.

e) $13,5-7$

Partiendo de eis hymâs con que termina el v. 4, Pablo se centra en la segunda persona del plural y dirige una apelación a la comunidad organizada en torno a la raíz dokimázo, introducida ya en el v. 3 con dokimén. En estos tres versículos aparece 5 veces. El verbo (dokimázete) 1 vez en 5a, las otras 4 son el adjetivo (adókimoi 3 veces, dókimoi 1 vez). En nuestro texto dokimázete habría que traducirlo por «examinad» ${ }^{109}$ y dókimoi-adokimoi por «calificados» -«descalificados» después de una prueba ${ }^{110}$. La dokimé sería la «prueba», «evidencia» o "verificante» del ser dókimos ${ }^{111}$. A estas palabras hay que añadir peirázete (v. 5), que en nuestro contexto es prácticamente sinónimo de dokimázete ${ }^{112}$.

Los razonamientos de Pablo deberían haber llevado a los corintios a dudar de sus seguridades, de sus opiniones sobre lo que un apóstol tiene que ser y hacer, sobre el carácter de su mediación y, por consiguiente, sobre las propias convicciones de la comunidad acerca de su fe cristiana ${ }^{113}$. Es ahí donde entra la propuesta radical de Pablo: deben examinarse a ellos mismos, si están en la fe (heautoùs peirázete ei estè en têi pístei, heautoùs dokimázete) (5a), en vez de centrar su prueba sólo en el Apóstol. Con Barret, que a su vez sigue a Wendland, hay que entender la expresión «estar en la fe» como sinónima de la paralela al final del versículo: hóti Iesoûs Christòs en hymîn ${ }^{114}$. Los corintios deben considerar si precisamente ellos (los autores notan la posición enfática del pronombre heautoús), son verdaderamente cristianos. Hay cierta ironía en la pregunta paulina ${ }^{115}$. Es claro que los corintios creen que pueden examinar

109. Cfr. W. BAUER, Griechisch-Deutsches Wörterbuch zu den Schriften des Neuen Testaments und der ubrigen urchristlichen Literatur. Berlin 1958, c. 401, s. v., 1.

110. Id., 402, s. v., 1.

111. Id., 402, s. v., 2, Cfr. también H.D. BETz, o.c., p. 133. E.-B. Allo, o.c., pp. 337s: «dokimé et les mots de même famille qui vont suivre, dokimázete, adókimoi, dókimoi, expriment d'un seul mot des notions qui étaient tout à fait entrées dans la vie quotidienne des Grecs (grâce aux 'dokimasies' des entrées en charge, en jouissance de droits, aux jeux, aux concours, etc.), mais qui, pour être comprises, ne peuvent se rendre en français que par des périphrases».

112. Cfr. W. BAÙER, o.c., c. 1269, s. v., $2 \mathrm{a}$.

113. Cfr. H.D. BETz, o.c., p. 133: «Gingen die Korinther in den Dialog in Unsicherheit über ihren Gründer und Apostel, so sind sie hernach unsicher auch uber die Gegner und über sich selber. In diesem kritischen Augenblick schiebt Paulus ihnen die Entscheidung zu: sie sind es, die nach der 'dokimé' des Paulus gefragt haben, sie selber müssen sie auch finden. Die ganze Argumentation des Paulus hatte nur ein Ziel, nämlich die Korinther wieder zu offnen und bereit zu machen, die Frage, die sie bereits beantwortet hatten, noch einmal kritisch zu überdenken».

114. C.K. BARRetT, A Commentary..., p. 338.

115. Id., 338. 
su propia fe y que son verdaderamente cristianos. Lo contrario sería ridículo, como el mismo Pablo hace ver con el inciso que añade al final del v. 5: «a menos que estéis descalificados».

La conclusión que los corintios deben sacar si examinan su propia fe y ven que son dókimoi es que Pablo no es adókimos sino dókimos (v. 6). Los comentaristas citan aquí 1Cor 9,1-2. El razonamiento de Pablo sería: «si vuestra fe es auténticamente cristiana, ¿quién os la ha comunicado? ¿no he sido yo?» ${ }^{116}$. Con todo, conviene acentuar el aspecto interno, de contenido, en la relación del apóstol con la comunidad, más que la circunstancia externa (ser el primero en predicar a los corintios). Pablo apela a la experiencia de «Jesucristo en vosotros». Ésta es la única verificación. Como él, también los otros misioneros habían predicado a Cristo a su manera. Por tanto la única posibilidad para el discernimiento era considerar la experiencia cristiana en su núcleo más radical al margen de toda postura partidista. De un análisis que reúna tales condiciones es de donde puede salir cuál de los apóstoles es el dókimos ${ }^{117}$. Pero quede claro que Pablo espera salir campante de la prueba. ¿Por qué? Lo hemos visto ya anteriormente. Su experiencia de Cristo, la que ha comunicado, reúne todos los requisitos que exige una prueba semejante. Él no persigue ningún interés personal, sólo dar paso a Cristo y la edificación de la comunidad. Su comportamiento respetuoso y desinteresado lo prueba. Esto es lo que trata de decir con un lenguaje paradójico en los tres versículos siguientes.

En el v. 7 Pablo dice que no le importa aparecer como dókimos ante la comunidad (cfr. 12,19). Puede muy bien ser tenido por adókimos. Lo importante es que los corintios no hagan el mal sino el bien ${ }^{118}$. Éste es el objetivo, no la aprobación del Apóstol por parte de la comunidad. Hablando así Pablo se muestra más legítimamente apóstol y más objetivo que nunca ${ }^{119}$.

\section{f) $13,8-9$}

Él mismo hace notar esta objetividad en el v. 8: «pues no podemos nada contra la verdad, sino en favor de la verdad» ${ }^{120}$.

116. Id., 338: «To throw doubt on his apostelship and apostolic message is to throw doubt on their own being as Christians; to affirm their own faith is to vindicate the preacher through whom they became believers».

117. Cfr. H.D. BETz, o.c., p. 134: «Ob sie selber dókimoi sind oder nicht, entscheidet sich freilich daran, wem sie die dokimé dann zugestehen werden, Paulus oder seinen Gegnern».

118. Sobre otras posibilidades poco probables de interpretar esta frase, cfr. E.-B. Allo, o.c., p. 339. C.K. Barrett, $A$ Commentary..., p. 339.

119. Cfr. C.K. BARretT, A Commentary..., p. 339.

120. Alétheia es usada seguramente aquí en un sentido bastante general, aludiendo a lo que es objetivo. Sólo que en el caso de Pablo, que repite una y otra vez que no le importa lo que puedan pensar de él, es claro que no se trata de una verdad democrática, sino de ló que responde a la 
En 9a refuerza la idea expresando algo parecido a lo que decía en el v. 7, ahora en clave de fuerza y debilidad: «Pues nos alegramos cuando nosotros somos débiles y vosotros sois fuertes». La expresión es muy cercana a 1Cor 4,10 (cfr. también 2 Cor 4,12). Es claro que Pablo está usando un poco de ironía y argumentando ad hominem, como lo hacía también en 1 Cor $4,10^{121}$. Después de todo lo dicho sobre la fuerza y la debilidad los corintios deberían avergonzarse de que los llamen fuertes, mientras su Apóstol, que tenía muchas más razones que ellos para presumir de fuerte, se alegra de ser débil. Más bien tendrían que sentirse débiles como él. De hecho Pablo pasa inmediatamente de esta afirmación a hablar de enmienda de la comunidad en $9 \mathrm{~b}$, como vamos a ver. Pero con ella da expresión una vez más a su actitud objetiva y desinteresada sobre su persona y solícita para con los corintios.

El v. 9b, quizá ocasionado por la última frase, algo provocativa, es la conexión entre lo que Pablo ha estado diciendo y la advertencia final: «Por lo que oro es por vuestra enmienda». Katártisis es hápax en el NT. Es una palabra derivada del verbo katartízein, usado en el versículo siguiente. El significado habitual es el de reparar, enmendar. Precisamente porque Pablo busca sólo la edificación de la comunidad en base a una experiendia radical de Cristo, el objeto de su preocupación y de su oración ahora es que la comunidad de Corinto vuelva a una vida cristiana más ordenada.

g) 13,10

La idea de corrección del v. 9b prepara la conclusión. «Por eso», porque quiere que las cosas se recompongan, Pablo repite en la conclusión el objetivo de la carta: «escribo esto ausente, para que presente no deba usar de severidad».

La continuación de la frase nos plantea un problema gramatical. ¿Hay que poner una coma delante de katá? Si la ponemos, la negación mé tendría efecto sólo hasta chrésomai. En ese caso, una traducción que anteponga katà tèn exousían... nos daría bien el sentido: «...para que, conforme a la autoridad que el Señor me dio para edificación y no para destrucción, no deba usar de severidad». Es decir, si Pablo consigue que los corintios razonen y lo acepten como él quiere, no tendrá que usar de severidad, lo cual estaría en armonía con la autoridad que él tiene, una autoridad que, como vimos, quiere ser reco-

voluntad de Dios vivida en la experiencia cristiana. Estamos siempre ante un problema de criterios. La verdad objetiva de Pablo juzgada democráticamente, podría parecer un subjetivismo monstruoso. Éste era también su problema con la comunidad de Corinto.

121. Cfr. C.K. BARRETT, A Commentary on The First Epistle to the Corinthians. London 1971, pp. 108, 110. 
nocida pacíficamente y no usar la violencia. Si no ponemos la coma, katà tèn exousían... caería también bajo la negación. El sentido que obtenemos entonces es: el uso de severidad, que Pablo trata de evitar, sería «conforme a la autoridad...». En este caso se afirmaría explícitamente que Pablo haría uso de su autoridad, si bien para un propósito para el que no le ha sido concedida, aclarado esto último por la oración de relativo parentética lo mismo que en $10,8^{122}$. La elección entre las dos traducciones no es decisiva. Se trata de una cuestión de acentos, pues una no excluye el significado de la otra. La primera no implica que Pablo no usaría su autoridad, la segunda no va en contra -al contrario, lo afirma, aunque parentéticamente - del modo en que Pablo entiende y quiere que sea reconocida esta autoridad. La primera pone el énfasis en este punto, la segunda en el uso efectivo que Pablo haría de su autoridad. En nuestra opinión es más probable la segunda, puesto que tiene su precedente en 10,8 , donde la misma oración de relativo se utilizaba parentéticamente, en un contexto donde la autoridad que Pablo tenía realmente daba la base para la amenaza de ir a Corinto con dureza.

En cualquier caso, la actitud de Pablo es inequívoca. Él ha estado explicando en la carta cuál era el tipo de autoridad que tenía y el modo en que pretendía que fuese reconocida. Con ello ha tratado de explicar el por qué de su comportamiento respetuoso - que para los corintios era ambiguo-y termina con la misma actitud, no se desdice. Pablo no quiere tener que usar su autoridad con riesgo de destrucción. Por eso apura los avisos lo más posible. A la luz de lo dicho sobre $12,20-13,4$ podemos comprender cuánto le importaba a Pablo advertir hasta que ya no hubiera nada que perder. Algo grave tenía que ocurrir para que él se decidiese a actuar con severidad. Sigue advirtiendo hasta el final, pues sabe que la prueba de su legitimidad no es tan evidente para los corintios. Ellos están acostumbrados a otros valores y podría ocurrir que toda su argumentación no haya producido el efecto esperado y los corintios sigan considerando que Pablo se atreve en las cartas, pero no cuando está presente.

\section{Conslusiones}

El análisis del párrafo conclusivo no contradice nuestras conclusiones sobre el párrafo inicial. Pero nos ha hecho profundizar en las perspectivas que allí quedaron abiertas.

Pablo sigue combatiendo por mantener su autoridad en Corinto. Pero aparecen claramente en su pretensión algunos elementos que la hacen singu-

122. Así C.K. BarretT, $A$ Commentary..., p. 341, siguiendo a Lietzmann y Wendland. 
lar, la separan inequívocamente de la de los intrusos y dibujan también el perfil de una posible respuesta de la comunidad:

a) Independencia de la opinión de la comunidad. Pablo no ha dicho todo lo que ha dicho para defenderse ante la comunidad. Él habla «ante Dios en Cristo», para edificación de los corintios. Es decir, para su edificación sí, pero sin que le impongan condiciones.

b) Objetividad y relativización de su propia persona. Pablo deja claro que no se trata de quién debe captarse a la comunidad, sino de una cuestión objetiva, de la auténtica edificación de la comunidad y su adhesión a Cristo. Lo importante es que ésta se dé cuenta de en qué consiste realmente hacer el bien, cuál es la experiencia cristiana radical. Por eso la prueba que buscan los corintios sobre la legitimidad del apostolado de Pablo debe empezar por revisar la experiencia de Cristo que la misma comunidad tiene. Si ella se da cuenta de que su experiencia cristiana corresponde a la raíz, entonces debería reconocer que Pablo es dókimos. Pero este reconocimiento es secundario para Pablo.

c) Autoconciencia especial. Pablo está convencido de que su comportamiento responde a la misma experiencia de Cristo en él. Por eso no teme afrontar las relaciones con los corintios respetando su libertad, más aún, exigiéndola. Ellos deben aceptar a Pablo, pero porque ven en base a criterios objetivos que tienen que aceptarlo. En razón de esa autoconciencia Pablo se siente con la fuerza de ir a Corinto con severidad si el conflicto con la comunidad se hace irreversible. Esto no sería pisotear la libertad antes exigida, sino llevar el trato en libertad hasta las últimas consecuencias. De hecho la visita dura se ha visto claramente como una medida fuera de programa que seguiría a un fracaso. Sería una especie de último testimonio del apóstol después de todos los avisos, cuando ya no hay nada que perder. Podría llevar a la destrucción, es decir, al mutuo rechazo - lo cual exige libertad por ambas partes- y, por consiguiente, a la ruptura de Pablo con la comunidad. Es curioso que Pablo no hace ninguna alusión al estado de cosas que seguiría a tal intervención. Toda su energía se concentra en decir a los corintios que está en sus manos evitarla.

Todo esto nos lleva a reflexionar más sobre la posición de Pablo y la posición de la comunidad en el conflicto. Pues lo que Pablo pretendía requiere ciertos presupuestos en la comunidad, que quizá no existían. $Y$ sus mismas pretensiones, en oposición a las de los otros misioneros, están formuladas de una forma paradójica, que requiere mayor estudio.

Pablo dice que no le importa ser reconocido como dókimos por la comunidad, con tal de que ésta siga el recto camino. Pero, en realidad, lo que se ve no sólo en estos capítulos, sino en toda la correspondencia corintia, es una comunidad que no es capaz por sí misma de profundizar en la experiencia de 
Cristo. Las frases de Pablo que tratan de dialogar objetivamente contrastan con la realidad: una comunidad que no tiene claros los criterios y necesita de mediadores (apóstoles) que le den seguridad.

La experiencia dice que un grupo a la larga tiende a regirse por los mecanismo de grupo: acepta más un líder que esté presente y no ausente, que goce de un prestigio reconocido por su origen y no sea un desconocido o advenedizo, que manifieste las dotes que a un grupo le gusta ver en sus líderes, que no exija demasiados cambios de mentalidad, pero que dentro de esa adaptación a los criterios del grupo tenga fuerza para imponerse y dé seguridad. Pablo no contaba con muchas posibilidades de seguir siendo una mediación indiscutida, frente a la aparición de otros que estaban dispuestos a adaptarse a estas condiciones, más aún, que las vivían espontáneamente. Él no era alguien que permanecía siempre en la comunidad; su misión era predicar el evangelio en terrenos siempre nuevos y, por lo tanto, su presencia en las comunidades que fundaba era siempre transitoria. Su conexión con las autoridades de Jerusalén era dudosa y él no hacía nada por aclararla (no usaba cartas de recomendación). No hacía alarde de su origen o de su personalidad rica. No se imponía por la fuerza, sino que se dirigía a la capacidad de discernimiento de las personas. No partía de los criterios del grupo, sino de su experiencia de conversión a Cristo.

En cualquier caso, lo que está claro es que la cuestión objetiva de la edificación de la comunidad iba ligada indisolublemente a la mediación del apóstol evangelizador y a su cualidad de líder, a su influjo sobre esa comunidad y al reconocimiento que ésta hace de él. Por eso no es extraño que nuestros capítulos estén centrados realmente en el problema del cuál es el apóstol que prevalece, quién es el dókimos, quién es el que la comunidad reconoce y propone. Una constatación la tenemos en 12,11a. Pablo dice allí que son los corintios los que le han obligado a hacer el loco, pues él debería ser recomendado por ellos.

Que Pablo había visto que las comunidades necesitaban de alguien que mediara su experiencia de fe, es evidente. El mero hecho de escribir cartas a sus comunidades adoctrinándolas lo prueba. Él mismo dice a los corintios en 1Cor 3,1-3 que son imperfectos y que no ha podido hablarles como a perfectos. Pero lo que llama la atención es precisamente el modo en que Pablo habla de esta relación suya de mediador de la fe con la comunidad. Es el estudio de este modo el que nos hará ver la respuesta que Pablo esperaba de los corintios en toda su complejidad. 


\section{EXCLUSIVIDAD DE PABLO COMO MEDIADOR EN LA CORRESPONDENCIA CORINTIA}

Ya hemos visto el modo paradójico en que Pablo defiende su relación con la comunidad en nuestros capítulos. A nadie, quizá sólo a él, se le habría ocurrido hacerlo así. No se defiende ante los corintios, sino que habla ante Dios en Cristo $(12,19)$. Él no quiere su dokimé, sino la de los corintios $(13,5-7)$. Aunque, en realidad, espera que todo ello sea su dokimé. Evidentemente a Pablo le importaba, y mucho, su relación con los corintios. Una relación que, como hemos visto en el párrafo inicial, debería consistir según él en que su autoridad fuera reconocida sin discusiones, para que no tuviera que mandar. Todo en un contexto de amor como entre padre e hijos. A Pablo le importaba también subrayar esta relación de amor: 11,$11 ; 12,14-15.19 b$. Se descubre, pues, un contraste curiosísimo entre las expresiones de apego y las de independencia.

La perplejidad en este sentido llega al extremo si consideramos lo que dice Pablo en 11,2-3: «Pues estoy celoso de vosotros con celos de Dios, pues os desposé con un solo hombre para presentaros como casta virgen a Cristo. Pero temo que, como la serpiente engañó a Eva con su astucia, sean corrompidas vuestras mentes de la sinceridad y la pureza ${ }^{123}$ para con Cristo». Pablo está en el lugar del padre $(12,14)$ que está desposando a su hija ${ }^{124}$. «Un solo hombre» (heni andrí) no es alguien distinto de Cristo ${ }^{125}$, sino que realza el hecho de que los corintios están desposados con una sola persona ${ }^{126}$. «Estoy celoso» (zelô) aquí, en este contexto en el que se habla de esposos y de seducción, hay que entenderlo en el sentido fuerte ${ }^{127}$. La presentación a Cristo tendría lugar seguramente en su venida y el desposorio se refiere a la conversión de los corintios ${ }^{128}$. Pablo dice que está celoso con los mismos celos de Dios ${ }^{129}$. ¿Por

123. Conservamos la lectura larga, apo tes haplotetos kai tes hagnotetos, de los mejores testigos: $\mathrm{p}^{46} \mathrm{~S}^{*} \mathrm{~B}$ F G 3381104 (326) pc a r sy ${ }^{\mathrm{h}^{* *}}$ co; Pel, contra la lectura breve (omit. kai tes hagnotetos) de $\mathrm{S}^{2}$ (D $\left.{ }^{2}\right) \mathrm{H} 0440121 \mathrm{a} 0243 \mathrm{M}$ (b) $\mathrm{f}^{*} \mathrm{vg}$ sy ${ }^{\mathrm{p}}$. La desaparición de la segunda palabra se explicaría por homoteleutón. Cfr. B.M. METzGer, o.c., p. 583. Para la opinión contraria cfr. C.K. BARRETT, $A$ Commentary..., p. 270: «...the addition was problably suggested by pure in verse 2 (Lietzmann). The variable position of 'purity' confirms its inauthenticity».

124. Sobre la voz de verbo, cfr. C.K. BARRETT, A Commentary..., p. 272: «Paul uses the middle, instead of the more usual active voice, of harmózein, perphaps because of his personal concern in the matter».

125. Cfr. E.-B. Allo, o.c., p. 277.

126. Cfr. C.K. BarretT, A Commentary..., p. 272.

127. Id., 272. E.-B. Allo, o.c., p. 275.

128. Cfr. C.K. BARReTt, A Commentary..., p. 272.

129. Theoa zéloi podría ser considerado un simple superlativo, como ocurría en el caso de 10,4 , «but hier the context requires the full force of the words; it is God's jealousy that lies behind Paul's» (C.K. BARretT, A Commentary..., p. 272). 
qué? Porque él es el mediador en este desposorio. Más aún, gracias a él este desposorio se ha llevado a cabo. Si la esposa no es fiel su posición se ve comprometida y se siente con el derecho a tener celos en nombre de Dios. Es una situación singular, ya que Pablo dice tener celos por Dios, no por él. Porque según él cree la novia está a punto de ser seducida por otro (v. 3) ${ }^{130}$. Pablo se está refiriendo evidentemente, como lo prueba el v. 4, a la acción del erchómenos que «predica otro Cristo». Es decir, los intrusos serían mediadores no del mismo Cristo, sino de otro. Por consiguiente hacerles caso es ser infieles al único esposo. Pero si consideramos el problema desde el punto de vista de los intrusos, serían ellos los que se tienen por los auténticos mediadores del único esposo, del único Cristo. De nuevo el problema de la pureza o impureza de la comunidad con respecto a su esposo, Cristo, está visto a través del otro problema del auténtico mediador.

De todas formas lo que a nosotros nos interesa más de este texto es la vehemente contundencia con que Pablo pretende ser un mediador exclusivo entre la comunidad y Cristo. Hasta el punto de que se insinúa la pregunta de si no será este exclusivismo de Pablo el que le haya hecho juzgar con excesiva dureza a los otros misioneros ${ }^{131}$.

Nuestro trabajo ahora consiste en recorrer la correspondencia corintia a la búsqueda de textos que nos aclaren algo las pretensiones de Pablo sobre su relación con la comunidad ${ }^{132}$. ¿Hay algo de cierto en la sospecha de exclusivismo que suscita 2 Cor 11,2-3?

\section{1 Cor $1-4$}

Ya Baur ${ }^{133}$ constató que en este texto Pablo defiende su ministerio. Así lo ha corroborado más recientemente Dahl ${ }^{134} \mathrm{y}$ también Vielhauer ${ }^{135}$. Repeti-

130. No podemos aquí ocuparnos de la elaboración de la historia de Adán y Eva a que alude el v. 3. Cfr. C.K. BARrett, «Paul's opponents...», pp. 239s.

131. Cfr. G. TheISSEN, o.c., p. 42: «...for examining in terms of their tipical characteristics the self-understanding of the missionaries who are competing in Corinth. For such a reconstruction we are largely dependent on Paul's statements. His objetivity in repeating what others have said is to be doubted. Whoever can intemperately defame his competitors as false apostles and servants of Satan, and even feel obliged to anticipate their eternal fate $(2 \mathrm{Cor} 11,14 \mathrm{f})$, will have a distorted perspective on many things».

132. Es claro que no podemos hacer una exégesis detallada de esos textos. Solamente tratamos de extraer de ellos rasgos evidentes que sirvan para esclarecer nuestros hallazgos.

133. F. Ch. BAUR, «Die Christuspartei in der korinthischen Gemeinde, der Gegensatz des paulinischen und petrinishen Christentums in der ältesten Kirche, der Apostel Petrus in Rom»: Tübinger Zeitschrift für Theologie, 1831, Heft 4, pp. 61-206.

134. N.A. DAHL, a. c.

135. Ph. Vielhauer, «Paulus und die Kephaspartei in Korinth»: NTS, 21 (1974-75) 341352. 
das veces nos hemos referido ya a este texto al estudiar el nuestro. Los contactos muestran que el modo en que Pablo vivió esas dos situaciones no debió ser en el fondo muy distinto. $\mathrm{Y}$ hemos visto que el problema de base podía ser muy semejante. En la comunidad de Corinto habían surgido contiendas entre los grupos que apoyaban a los distintos misioneros (o que apelaban directamente a Cristo) (1,11-12). Los nombres de estos misioneros: Pablo, Apolo y Cefas. la reacción de Pablo es más compleja de lo que una lectura superficial del texto podría hacer pensar.

Por un lado trata de hacer ver que Cristo no está dividido, que sólo en su nombre han sido bautizados $(1,13-16)$; que los distintos misioneros tienen distintas funciones, pero todos son colaboradores de Dios y servidores de la comunidad, la cual es plantación y construcción de Dios (3,5-9); ninguno de los misioneros es nada, el que da el crecimiento es Dios $(3,7)$; no hay razón para gloriarse en uno o en otro, puesto que los misioneros son de la comunidad, la comunidad de Cristo y Cristo de Dios (3,21-23). En resumen, que no hay motivo de división, pues al final lo único que importa es que la comunidad esté en la fe de Cristo que es común.

Por otro lado hay que considerar algunos rasgos que son los que en la situación concreta de Corinto desequilibran la balanza en favor de Pablo:

a) Antes que nada conviene recordar la actitud ya notada de Pablo, que se siente completamente independiente de cómo pueda ser juzgado por los hombres $(4,3)$. Ni siquiera él se juzga. El que lo juzga es Dios $(4,4)$. Tampoco los corintios deben juzgar, por lo tanto $(4,5)$.

b) Si bien las funciones de cada misionero son secundarias, no deja de ser cierto que Pablo es el que ha plantado. Se trata del primer momento en el llegar a la fe de los corintios. Hasta qué punto es «especial» esta misión lo dice Pablo al desarrollar la imagen del edificio. Él ha sido el arquitecto que ha puesto el cimiento. Este cimiento es Cristo. Y nadie puede poner otro. Los que vengan detrás deberán acomodarse a él $(3,10-17){ }^{136}$.

c) Pablo escribe estas cosas a los corintios como un padre acoseja a sus hijos. Pues él sólo es quien los ha engendrado en Cristo Jesús, aunque tengan muchísimos pedagogos (4,14-15). «Engendrar en Cristo» (en gàr Christôi Iesoû dià toâ euaggelíou egò hymâs egénnesa) tiene un sentido muy fuerte. A este respecto es interesante tener en cuenta la nota de Saillard sobre gennân: Cuando este verbo en el NT se refiere al nuevo nacimiento de los cristianos por la palabra de Dios (como en nuestro caso) y no tiene por sujeto a Dios mismo, está en perfecto pasivo (1Jn 3,9; 1 Pe 1,23), mientras que en 1 Cor

136. Se ha descubierto aquí una polémica antipetrina. Cfr. Ph. VIELHAUER, a.c. Hay muchos argumentos importantes en su favor. Pero no es éste el momento de ocuparnos de ello. 
4,15b Pablo mismo es el que engendra ${ }^{137}$. Es él quien les ha transmitido la persona de Cristo y los ha hecho entrar en una vida completamente nueva ${ }^{138}$. Por eso puede proponerse como modelo a la comunidad entera: mimetai mou gínesthe $(4,16)$ y sus caminos en Cristo deben ser recordados $(4,17)$. Palabras que suenan con una contundencia inusitada.

En conclusión, Pablo no excluye otros misioneros. Pero los corintios deben tener claro que el punto de referencia obligatorio, el normativo, es la misión de Pablo, porque en ella ha sido transmitido Cristo. Las palabras de Dahl expresan muy bien la situación:

At the beginning Paul asks for the mutual concord of the brethren; at the end of the section if not before, the reader understands that Paul at the same time asks his children to concur in harmony with their father in Christ. This is well brought out by John Knox, who has written, with reference to 1Cor 1-4; «He wants his converts to stand firm, not only in the Lord, but also in their loyalty to him» ${ }^{139}$.

Esta seguridad que tiene Pablo y que pide lealtad está a su vez dispuesta a desacreditar a cualquier arquitecto que no reconozca que los cimientos que él ha echado son válidos, precisamente en cuanto cimientos ${ }^{140}$. Esto sería más claro si en lo dicho en la nota 136 sobre la polémica antipetrina hay algo de cierto. Pero se hace ya palpable en el tono amargo con que Pablo se lamenta. Los corintios creen haberse enriquecido, reinar sin Pablo $(4,8)$. Se han inflado, pues creían que no iba a ir a Corinto $(4,18)^{141}$. Pablo, el eterno ausente, se empeña sin embargo en conservar su relación de privilegio. ¿Cómo podría si no responder a las dudas doctrinales y morales de la comunidad? ${ }^{142}$. En estos capítulos aparece clara la autoconciencia de Pablo, pero también, precisamen-

137. M. Saillard, «C'est moi qui, par l'Evangile, vous ai enfantés dans le Christ Jésus (1Cor 4,15)»: Rech. Sc. Rel., 56 (1968) 40.

138. Id., 39.

139. N.A. DAHL, a.c., pp. 319s.

140. Quizá esto podría explicar la virulencia de Pablo en 2 Cor 11,4 . Cfr. a este respecto N.A. DAHL, a.c., p. 326 , nota 2 : «Even in 2 Cor 11,4 the point is the identity of Jesus and not a variety of Christologies. The true Jesus is identical with himself, as Paul preached him and made him the foundation of the church at Corinth. A 'Jesus' who does not recognize this foundation must be another, a false Jesus. The same holds true for a Spirit and a 'Gospel' which is received as if Paul had not already preached the gospel and as if those who then believed had not already received the Holy Spirit».

141. Id., 319, 325. El autor concede una gran importancia al dato de la ausencia de Pablo, como desencadenadora de las contiendas entre los grupos.

142. Id., 325-331. La función de estos capítulos sería según Dahl - lo que resulta convincente - precisamente la de devolver a Pablo la posición de autoridad sobre toda la comunidad, puesta en duda por los que no se declaraban de su grupo (incluso los del partido de Cristo). Era el único modo en que podía aventurarse después a aclarar problemas. 
te por eso, su pretensión de tener con la comunidad una relación especial, que se traduce en un lenguaje exigente y tierno al mismo tiempo, lleno de confidencias. Pablo no podía consentir que si era padre lo llamasen subordinado. No estaba dispuesto a aceptar que por cuestiones humanas de segundo orden se tuviera en menos su apostolado. En este sentido jugaba al «todo o nada», lo cual hay que reconocer que es muy poco «pastoral». Si los corintios lo admitían, debía ser por lo que había hecho, no «como uno más». Si Pablo llegaba a ser considerado por los corintios "como uno más», es que no habrían entendido profundamente y entonces tendría que ir con la vara $(4,21)$. ¿Pero de qué serviría ya esto para los que no se consideraban de su grupo?

\section{Otros textos}

Hay otros textos en la correspondencia corintia que son reflejo al mismo tiempo de esa extraordinaria autoconciencia paulina y de la intimidad exclusivista en la relación creada con la comunidad:

a) 1Cor 9,1-2. En un contexto polémico también, Pablo afirma su apostolado. Simultáneamente dice a los corintios que ellos son su obra en el Señor. El v. 2 es una muestra de lenguaje confidencial que tiende a excluir a otros.

b) 1Cor 11,1-2. En el v. 1 aparece tanto la seguridad apabullante que Pablo tiene de que sigue a Cristo, como su carácter normativo para los corintios. Es casi como decir que él es la actualización de Cristo para la comunidad. Por eso puede alabar en el v. 2 que la comunidad se acuerde de él en todo y de lo que les enseñó.

c) 2 Cor 1,14. Pablo es la gloria de los corintios, lo mismo que los corintios serán la suya en el día del Señor Jesús. Lenguaje éste que sólo en un contexto de afecto especial y único, no repetible, se puede entender.

d) 2Cor 1,23-2,11. Es éste un texto que ya hemos citado anteriormente. Pablo, al mismo tiempo que afirma que no es tirano de la fe de los corintios $(1,24)$, puede decir que ha escrito la carta dura para ver si son obedientes en todo (2,9). Y todo ello en medio de efusiones por parte de Pablo: su alegría es la alegría de los corintios y viceversa $(1,24-2,2)$.

e) 2Cor 3,1-3. Pablo no necesita cartas de recomendación para los corintios como los otros misioneros. La comunidad misma es su carta de recomendación. Carta escrita en corazones de carne, no en piedras. Éste es un lenguaje lleno de afecto y que desborda convicción de que la relación entre Pablo y la comunidad es única, especial. Nadie podría decir esto de la comunidad más que Pablo. 
f) 2Cor 4,1-6. Especialmente interesantes para nosotros son los vv. $2 \mathrm{~b}$ y 5. Pablo no se predica a sí mismo, sino al Señor Jesús. Él es el siervo de la comunidad dià Iesoûn (v. 5). Pero puede recomendarse a sí mismo a toda conciencia humana en la presencia de Dios (v. 2b). Es difícil encontrar palabras más expresivas para hablar de la propia autoconciencia. Pablo no se recomienda a sí mismo por sí mismo, sino porque está convencido, por encima de todo juicio humano, que predica a Cristo y que es Cristo quien lo recomienda (comparar con 2Cor 10,12-18).

g) 2Cor 5,11-12. Pablo espera estar al descubierto ante los corintios, pues lo está ante Dios. No trata de recomendarse ante ellos, sino de darles ocasión para que se gloríen de él ${ }^{143}$, en contra de los que se glorían sin razón. Así pues, si Pablo pone las cosas en su sitio con respecto a su persona, no es como fruto del deseo de recuperar la popularidad perdida ante el grupo. Lo hace en virtud de una colosal autoconciencia. Sabiendo lo que su persona representa, los corintios podrán gloriarse de él.

h) 2 Cor 6,11-12; 7,2-4. Pablo se desborda de afecto. Ha abierto completamente su corazón a los corintios y pide lo mismo a cambio. Lo hace como un padre con sus hijos (hòs téknois légo) $(6,12)^{144}$.

i) 2 Cor 7,7. Pablo se alegra sobremanera de que los corintios muestren un deseo y celo especial por su persona. Todo el párrafo $(7,5-16)$ es una expresión única de la relación de afecto intenso entre Pablo y la comunidad. Pablo estaba interesado en que los corintios mostraran interés por él. Él mismo confiesa que, cuando escribió después de la injuria sufrida, no era por este motivo, sino para que se pusiera de manifiesto entre los mismos corintios su solicitud por Pablo. Que esto se haya producido es de gran consuelo para él $(7,12-13)$. En 7,16 Pablo se alegra de confiar totalmente en los corintios. Suena a lo que un padre podía decir a sus hijos. No se puede pensar que más de una persona pudiera decirle esto con el mismo derecho a una comunidad.

j) 2 Cor 9,4b. Si Pablo queda avergonzado porque los corintios no estaban preparados en la cuestión de la colecta, son ellos mismos los que quedan en feo.

143. Los autores no dudan aquí en aceptar la lectura hemon en vez de hymon, que aunque aparezca en tan excelentes manuscritos como $\mathrm{p}^{46} \mathrm{~S} \mathrm{~B}$, es considerada sin sentido. Con todo, es prudente, como hace C.K. BARRETT, $A$ Commentary..., p. 162, dejar al menos el interrogante: «yet how is it that the error, if error it is, is found in hardly any but the oldest and best MSS?».

144. Cfr. supra, cuando hablamos de 1 Cor 4,14-15. 


\section{Conclusiones}

Después de leer estas cosas, uno no se extraña de oír a Pablo que está celoso de los corintios con celos de Dios $(11,2)$. Él era un iniciador. No iba a comunidades cristianas ya formadas, sino a terreno virgen. Por otro lado está convencido de que su experiencia cristiana es absolutamente radical, actualiza la vida de Cristo de tal manera que puede proponerse a sí mismo en todo momento como modelo. Esto le da el derecho a considerar ilegítimo cualquier apostolado que no reconozca el suyo, pues significa que es incapaz de reconocer el auténtico fundamento, que es Cristo. A la misma comunidad no le queda más alternativa en la práctica que darse cuenta de esto y -aunque esto segundo no sea exigido- entablar una relación de hijos a padre, íntima, afectuosa y exclusiva con éste su primer apóstol, con Pablo.

\section{CONCLUSIÓN GENERAL}

Con el último apartado hemos visto cómo esperaba Pablo que se concretase la respuesta de los corintios: aceptarlo como la mediación única y fundante de su fe, lo mismo que los hijos, que sólo tienen un padre que los ha engendrado. Pero esto es inseparable de lo problemática que una pretensión de este tipo se ha ido descubriendo en nuestro estudio. Leyendo el resto de las cartas de Pablo se comprueba que también en ellas aparece esta exclusividad en la relación de Pablo con sus comunidades (a Pablo le importaba ese posesivo, a pesar de que la obediencia se debía sólo a Cristo). Pero hay algo específico en la correspondencia corintia, y más concretamente en 2Cor 10-13. La persistencia de los conflictos entre Pablo y otros misioneros en Corinto puso serios interrogantes a esta relación exclusiva de Pablo, el padre, con sus hijos. El intento de Pablo por restablecer la evidencia de esta relación se hizo paradójico en extremo en los capítulos estudiados. En ellos aparece casi contradictoriamente claro que quien está pidiendo una posición indiscutida de liderazgo es alguien que ha rechazado deliberadamente, por considerarlo incompatible con la experiencia cristiana radical que predica, aparecer como líder. El mismo Pablo en el curso de la argumentación pone las cosas más difíciles todavía cuando trata de separar la dokimé del fruto de su misión de su propia dokimé. Era casi como estar provocando a la comunidad para que lo rechazara. ¿Cómo era posible reconocer una dokimé sin reconocer también la otra?

Una comunidad en conflicto entre varias ofertas tiende siempre a aceptar un modelo más cercano a sus aspiraciones, más tangible, y a proclamar como líderes a quienes proponen este modelo. Y nosotros tenemos el derecho de preguntarnos - por lo menos - si una comunidad ha sido capaz alguna vez de en- 
tender radicalmente un discurso como el de Pablo en 2 Cor 10-13, si en todo grupo, acepte o rechace a sus mediadores, no prevalecen a la postre en gran parte los criterios sensacionalistas, las aparentes dokimaí, la propaganda ${ }^{145}$, las cuestiones de prestigio y el espíritu sectario. Habría que preguntarse si los verdaderos apóstoles no están condenados, como Cristo, a ser rechazados por los grupos mientras viven - rechazados en lo más radical de su experiencia, aunque sean aceptados como figuras de prestigio- y canonizados cuando mueren quizá también por razones secundarias.

De hecho sabemos que la relación de Pablo con la comunidad de Corinto cintinuó ${ }^{146}$. Pero la crítica literaria no nos permite concluir cómo. Nada sabemos de si Pablo tuvo que ir finalmente con severidad o si los corintios se pusieron de su parte al leer la carta. Pero aunque fuera cierto esto último, nunca sabríamos exactamente por qué lo hicieron. ¿Fue porque se dieron cuenta de que Pablo les transmitía realmente a Cristo crucificado por debilidad y vivo por la fuerza de Dios, o porque vieron que era más fuerte que los intrusos? Podríamos generalizar más nuestra pregunta: ¿Puede una comunidad hacer una distinción tan clara como la hacía Pablo entre esas dos cosas? La reconciliación que vemos en 2 Cor 1,1-2,13 + 7,5-16 es suficientemente ambigua como para permitir una duda legítima. Y quizá debamos pensar que en toda reconciliación posible de alguien tan poco adaptable como Pablo (en lo que considera el núcleo de su experiencia) con una de sus comunidades tiene que haber necesariamente algo de fracaso. Pues se trata de un fracaso que existe desde el momento en que la conversión de la comunidad es mucho menos radical. Un grupo - que depende de una mediación- es incapaz de una experiencia radical como la de Pablo. En este sentido podríamos decir que hay una contradicción teórica en la propuesta de Pablo. ¿Cómo puede alguien pretender ser el mediador de un grupo y pedirle que reconozca esta mediación con la misma clarividencia y libertad que él posee? Si el grupo llegara a ser tan clarividente y libre ya no necesitaría un mediador. El planteamiento dramático de Pablo tenía que caer necesariamente un poco en el vacío, leído ante una comunidad.

Puede haber influido mucho el temperamento de Pablo al tratar de recuperar el afecto y la obediencia incondicionales y exclusivos de su comunidad. En sus expresiones se detectan una gran pasión y susceptibilidad ${ }^{147}$. Otro tipo de carácter no habría hecho tanto el «loco», se habría resignado. Pero es peli-

145. Cfr. H.D. BETz, o.c., p. 134: «Die paulinische Unterscheidung läuft also hinaus auf die zwischen einer 'scheinbaren' Evidenz, die wir heute als 'Propaganda' bezeichnen würden, und wirklicher Evidenz»».

146. Cfr. supra, introducción.

147. Cfr. P. MAdros, Susceptibilité et humilité de Saint Paul dans sa seconde lettre aux Corinthiens. Jérusalem 1981. 
groso aislar aspectos de carácter en personas como Pablo. Precisamente porque no contamos con posibilidades de comparación, por la singularidad de su persona y de su experiencia, es aconsejable seguirla y tratar de descubrirla a través de su manifestación externa, también psicológica. Cuando Pablo afirma de un modo tan categórico y autoafirmativo su independencia del juicio de la comunidad existe ahí algo más que un modo de ser exagerado. Las expresiones de Pablo responden a algo más que un temperamento especial, incluso cuando plantea su relación con una comunidad. Hay en todo ello algo que responde a una experiencia humana única, algo que lo identifica, como él mismo decía, de un modo especial con el destino de Jesús de Nazaret, confesado Cristo en la fe.

Nuestro estudio tampoco se ha fijado mucho en conceptos generales de apostolado. Nosotros queríamos descubrir las pretensiones de Pablo, precisamente de Pablo. En su tiempo hubo más gente que practicó un tipo de misión semejante al suyo ${ }^{148}$. Pero no encontramos figuras que hayan dejado una huella como la suya, ni que hayan sido objeto tan grande de simpatías y antipatías como él, tanto en su vida como después de su muerte ${ }^{149}$. De nuestro trabajo debería resultar claro lo aventurado que es aplicar nociones generales y teóricas sobre el apostolado a Pablo o concluirlas de su experiencia para los otros. Y esto aun cuando sea el mismo Pablo quien generaliza. ¿No es sintomático que en 2Cor 10-13 aparezca su figura como apóstol opuesta a la de una pluralidad de apóstoles? Seguramente los otros no tenían las mismas pretensiones, se conformaban con menos. Alguien que, como nos muestra el relato de Gal 2,11-14, veía en juego la verdad del evangelio en detalles pacíficos para otros apóstoles debe ser protagonista de una experiencia no fácilmente accesible a muchos, más allá de los conceptos que utilice o del mundo cultural del que proceda. Un cristiano que lee hoy el Nuevo Testamento tiene derecho a pensar que es esta experiencia única de Pablo la que hizo de su actividad y sus cartas un punto clave en los orígenes de la fe cristiana y que su capacidad de comunicar a Cristo es actual y directa, independientemente de la discontinuidad existente entre su ministerio y los ministerios surgidos en sus comunidades.

Ángel RODRíGUEZ MERINO

148. Cfr. B. Holmberg, o.c., pp. 57-70.

149. Cfr. G. Luedemann, Paulus der Heidenapostel, II. Antipaulinismus im frühen Christentum. Göttingen 1983. 